\title{
Mid-infrared reflectance spectroscopy of synthetic glass analogs for mercury surface studies
}

DOI:

10.1016/j.icarus.2021.114363

\section{Document Version}

Accepted author manuscript

Link to publication record in Manchester Research Explorer

\section{Citation for published version (APA):}

Morlok, A., Renggli, C., Charlier, B., Reitze, M. P., Klemme, S., Namur, O., Sohn, M., Martin, D., Weber, I., Stojic, A. N., Hiesinger, H., Joy, K. H., Wogelius, R., Tollan, P., Carli, C., Bauch, K. E., \& Helbert, J. (2021). Mid-infrared reflectance spectroscopy of synthetic glass analogs for mercury surface studies. Icarus, 361, 114363. https://doi.org/10.1016/j.icarus.2021.114363

\section{Published in:}

Icarus

\section{Citing this paper}

Please note that where the full-text provided on Manchester Research Explorer is the Author Accepted Manuscript or Proof version this may differ from the final Published version. If citing, it is advised that you check and use the publisher's definitive version.

\section{General rights}

Copyright and moral rights for the publications made accessible in the Research Explorer are retained by the authors and/or other copyright owners and it is a condition of accessing publications that users recognise and abide by the legal requirements associated with these rights.

\section{Takedown policy}

If you believe that this document breaches copyright please refer to the University of Manchester's Takedown Procedures [http://man.ac.uk/04Y6Bo] or contact uml.scholarlycommunications@manchester.ac.uk providing relevant details, so we can investigate your claim.

\section{OPEN ACCESS}




\section{MID-INFRARED REFLECTANCE SPECTROSCOPY OF SYNTHETIC GLASS ANALOGS FOR MERCURY SURFACE STUDIES}

Andreas Morlok ${ }^{1}$

Christian Renggli ${ }^{2}$

Bernard Charlier ${ }^{3}$

Maximilian P. Reitze ${ }^{1}$

Stephan Klemme ${ }^{2}$

Olivier Namur ${ }^{4}$

Martin Sohn ${ }^{5}$

Dayl Martin ${ }^{6}$

Iris Weber ${ }^{1}$ Aleksandra N. Stojic ${ }^{1}$ Harald Hiesinger ${ }^{1}$

Katherine H. Joy ${ }^{7}$ Roy Wogelius ${ }^{7}$

Peter Tollan ${ }^{8}$

Cristian Carli ${ }^{9}$

Karin E. Bauch ${ }^{1}$

Joern Helbert ${ }^{10}$

${ }^{1}$ Institut für Planetologie, Westfälische Wilhelms-Universität Universität Münster, Wilhelm-KlemmStrasse 10, 48149, Germany

${ }^{2}$ Institut für Mineralogie, Westfälische Wilhelms-Universität Universität Münster, Corrensstrasse 24, 48149 Münster

${ }^{3}$ University of Liege, Department of Geology, 4000 Sart-Tilman, Belgium

${ }^{4}$ Department of Earth and Environmental Sciences, KU Leuven, 3001 Leuven, Belgium ${ }^{5}$ Hochschule Emden/Leer, Constantiaplatz 4, 26723 Emden, Germany

${ }^{6}$ European Space Agency, Fermi Avenue, Harwell Campus, Didcot, Oxfordshire, OX11 OFD, UK

${ }^{7}$ Department of Earth and Environmental Sciences, University of Manchester, Oxford Road, Manchester, M13 9PL,UK

${ }^{8}$ Intitut für Geologie, Universität Bern

${ }^{9}$ IAPS-INAF, Rome, Italy

${ }^{10}$ Institute for Planetary Research, DLR, Rutherfordstrasse 2, 12489 Berlin, Germany 
We have synthesized and analysed silicate glasses that are representative for the glasses on the

34 surface of Mercury by mid-infrared reflectance spectroscopy, based on high-pressure laboratory

35 experiments and the resulting compositions of the glass phase. The spectra are of interest for

36 investigating the surface of Mercury using the MERTIS (Mercury Radiometer and Thermal Infrared

37 Spectrometer) instrument on board of the ESA/JAXA BepiColombo mission.

Both powdered fractions and polished blocks have been analyzed. Powdered size fractions of 0-

$40 \mu \mathrm{m})$. Spectra for powdered bulk glasses (1.6 wt\% - $19.0 \mathrm{wt} \% \mathrm{MgO})$ show a single, dominating

41 Reststrahlenband (RB, 9.3 - $9.8 \mu \mathrm{m}$ ), a Christiansen Feature (CF; $7.6 \mu \mathrm{m}-8.1 \mu \mathrm{m}$ ), and a size dependent

42 Transparency Feature (TF; 11.6 - $11.9 \mu \mathrm{m}$ ). Micro-FTIR analyses of polished blocks of glasses (3.4 - 26.5

$43 \mathrm{wt} \% \mathrm{MgO}$ ) have characteristic bands at 7.8 - $8.2 \mu \mathrm{m}(\mathrm{CF})$, and $9.3-9.9 \mu \mathrm{m}$ (RB). Only few olivine

44 crystalline features were observed.

Spectral features correlate with compositional characteristics, e.g. $\mathrm{SiO}_{2}$ content or SCFM

$47 \mathrm{RB}$ are with $\mathrm{Mg} / \mathrm{Si}$. No simple mixture of glass spectra from this study is able to reproduce the entire

48 ground based spectrum of the surface of Mercury. However Mg-rich glasses reproduce identified

49 features at $8.5 \mu \mathrm{m}, 9.9 \mu \mathrm{m}$ and $12.4 \mu \mathrm{m}$.

50

51

52 


\section{Introduction}

Given the lack of meteorites or samples from the surface of Mercury (e.g., Weber et al.2016), our current knowledge of its surface chemical composition is primarily based on chemical measurements by X-ray (Schlemm et al., 2007), as well as gamma-ray and neutron (Goldsten et al., 2007) spectrometers onboard the MESSENGER spacecraft. Based on major element ratios from these observations, several different terranes with characteristic chemical compositions have been identified (Nittler et al., 2011; Peplowski et al., 2015; Weider et al., 2015; vander Kaaden et al., 2016; Peplowski and Stockstill-Cahill, 2019). In a refined model using multivariate statistics, Peplowski and Stockstill-Cahill (2019) identified seven terranes. Characterized by their Mg contents are following terranes: The High-Mg $(H M g)$ region, a Northern High-Mg region $(N-H M g)$, and the Rachmaninoff-Basin $(R B)$. Units with lower $\mathrm{Mg}$ abundances include the Northern Low-Mg $(N-L M g)$ terrane and a region that is also Al-rich ( $L M g-H A /$ region), which occurs mostly in the Caloris basin. A last unit characterized by its high Al is the High-Al (HAl) terrane. Defined by its $K$ content is the High-K $(I H K)$ terrane. Based on the chemistry, the rock types of these different terranes can broadly be described as komatiitic, boninitic, and andesitic (e.g., Weider et al., 2015; Peplowski and Stockstill-Cahill, 2019).

The chemical data provided by MESSENGER were the basis for the identification of the surface mineralogy and petrology of Mercury. One way is to model the mineral composition from the chemistry, (e.g., Cross et al., 1902; van der Kaaden et al., 2016; Solomon et al., 2018; Peplowski and Stockstill-Cahill, 2019). A further way to study the petrology of Mercury are laboratory experiments. High pressure experiments that studied phase equilibria of peridotite and partial melt compositions under hermean mantle conditions were performed by Charlier et al., 2013; Namur et al., 2016 and Namur and Charlier, 2017. These techniques suggested that the hermean surface mineralogy should be dominated by variable abundances of plagioclase, forsterite, diopside, and enstatite, with unconstrained proportions of silicate glasses. 
For Mercury, mid-infrared spectroscopy has only previously been undertaken using terrestrial

telescopic observations. Studies that cover larger surface regions (Donaldson-Hanna et al., 2007; Sprague et al., 1994, 1997, 2000, 2002, 2007; Sprague and Roush, 1998; Emery et al., 1998; Cooper et al., 2001) show some surface variation, with a mineralogy dominated by plagioclase and some pyroxene. Glassy silicate materials are difficult to identify in the mid-infrared owing to their rather featureless spectra.

83 Usually, only a single, broad band is visible in the region around $10 \mu \mathrm{m}$ (e.g., Speck et al., 2010; Morlok et 84 al., 2020a.) Earlier successful utilization of the thermal infrared wavelength range in planetary remote sensing covered the lunar surface (e.g., Sprague et al., 1992) and the Martian regolith (e.g., Bishop et al., 1995; Christensen et al., 2004).

This study focuses on the spectral properties of glasses relevant to Mercury's surface, which could have been formed by three major processes. First, explosive volcanism in the form of pyroclastic eruption-style volcanic activity occurred locally until about one billion years ago as evidenced by pyroclastic deposits (Goudge et al., 2014; Thomas et al., 2014; Murchie et al., 2015). Second, the surface of Mercury is dominated by lava flows. Magma quenching is very efficient in the hermean environment owing to the generally cold temperatures at the surface and at shallow depths. Therefore, it is

93 conceivable that the surface contains a significant portion of quenched glasses with a range of

94 compositions (e.g., Weitz et al., 1997; Kerber et al., 2011; Byrne et al., 2013; Charlier et al., 2013; Denevi

95 et al., 2013; Namur et al., 2016; Namur and Charlier, 2017). Third, rapid melting and quenching of rocks 96 occurred during high velocity impacts also central to the formation of the planet's surface. Mercury's 97 regolith is therefore expected to contain high amounts of impact derived glass (e.g., Hörz and Cintala, 1997; Warrell et al., 2010; Murchie et al., 2015). A further process that can produce a glass component on planetary surfaces is space weathering, which can amorphize the surfaces of mineral phases (e.g., Brunetto et al. 2014; Weber et al., 2020; Stojic et al., 2020). Warell et al. (2010) estimated a glass content of $20-45 \%$ for the hermean regolith based on spectral modelling of hermean surface data. 
103 spectra are needed for the accurate interpretation of future remote sensing spectra from the joint

104 ESA/JAXA BepiColombo space probe, which will arrive at Mercury in 2025, and start investigating the

105 innermost planet with a wide range of instruments in 2026 (e.g., Benkhoff et al., 2010, Hiesinger et al.,

1062010 and 2020; Rothery et al., 2020). Among the instruments is, for the first time, a mid-infrared

107 spectrometer, MERTIS (Mercury Radiometer and Thermal Infrared Spectrometer). It will map the surface

108 of the planet in the 7-14 $\mu \mathrm{m}$ spectral range, with a pixel scale of at minimum 500 meters or even lower,

109 depending on the orbit (Hiesinger et al., 2010, 2020). These mid-infrared emission features will permit

110 the detection of Mercury's surface mineralogy in much more detail than with earlier instruments (e.g.,

111 Hiesinger et al., 2020).

The aim of this study is to provide spectra of synthetic glasses covering a representative range of

113 compositions that are to be expected for regolith that formed by petrological processes under

114 appropriate conditions for Mercury. This is in contrast to earlier studies (Morlok et al., 2017b and 2020a)

115 which are based on quenched melts with the average chemical composition of the whole terranes and

116 thus representative of larger averaged areas. These glasses will also be used for future studies, where we

117 will mix these glasses with crystalline phases to create synthetic bulk analog mixtures similar to the

118 hermean regolith for additional spectral studies.

120 2. Samples and Techniques

$121 \quad$ 2.1. In Situ Glasses and Composition of Bulk Glasses

The glassy areas studied using micro-FTIR in run products from earlier high pressure laboratory experiments (Namur and Charlier, 2017) are in the following referred to as in situ samples. In these

124 experiments, melts with starting compositions of the various geochemical terranes on Mercury were 
equilibrated under different temperatures $\left(1100-1480^{\circ} \mathrm{C}\right)$, high pressure $(0.1 \mathrm{GPa})$, varying oxidation

126 fugacities relative to the iron-wuestite buffer ( $\Delta \mathrm{IW})$ from $\Delta \mathrm{IW}-7.2$ to -4.7 , and run times of 4 to $108 \mathrm{~h}$

127 (Namur and Charlier, 2017). The resulting run products (Table1) showed a wide range in modal

128 abundance of forsterite, diopside, plagioclase, enstatite, and quartz. The abundance of the glass

129 component varied from samples consisting entirely of glass to minimum contents of 21 wt\%.

The second group of glasses studied are referred to as bulk glasses. For the synthetic bulk

glasses, we used glass compositions based on the experimental runs in Namur and Charlier (2017) (for a

132 list see Table 2), which are based on the starting compositions of the high-Mg and low Mg northern

133 volcanic plains (HMg-NVP and $L M g-N V P$, respectively), Smooth Plains (SP), Inter crater Plain and Heavily

134 Cratered Terrains (ICP-HCT), and the High-Mg Province $(H M g)$. The intention is to cover a compositional

135 range expected for glasses on Mercury. The modeled compositions (sources see Table 2) used to prepare

136 the bulk glasses were for the low Mg endmember glass $159 \mathrm{Low}-\mathrm{Mg} \mathrm{C}$ an MgO content of $1.8 \mathrm{wt} \%$ and

13772.3 wt $\mathrm{SiO}_{2}$. Glass $158 \mathrm{Low}-\mathrm{Mg} \mathrm{B}$ has 5.1 wt\% $\mathrm{MgO}$ and 66 wt\% $\mathrm{SiO}_{2}$. The 'intermediate' sample with an

$138 \mathrm{MgO}$ content of $10.7 \mathrm{wt} \%$ and $\mathrm{SiO}_{2}$ at $61.3 \mathrm{wt} \%$ is $174 \mathrm{Low}-\mathrm{Mg} \mathrm{A} / \mathrm{I}$. The high-Mg composition end member is a glass with a calculated starting composition of $55.9 \mathrm{wt} \% \mathrm{SiO}_{2}$ and $21.8 \mathrm{wt} \% \mathrm{MgO}(181 \mathrm{High}$ $M g$ II). The comparison of the in situ glass spectra with the powdered bulk glasses from this study will serve as a quality control. We expect the spectral features of glass phases synthesized for this study to

142 be similar to the glasses from the run products from the high pressure petrological experiments. Mercury, sieved and powdered fractions (several grams) are needed, much more than the few mg 145 available from the run products of the elaborate high pressure laboratory experiments producing the in 146 situ samples (Namur and Charlier, 2017). 


\subsection{Synthesis of Bulk Glasses}

The bulk glasses were synthesized from reagent grade oxides $\left(\mathrm{SiO}_{2}, \mathrm{TiO}_{2}, \mathrm{Al}_{2} \mathrm{O}_{3}, \mathrm{Fe}_{2} \mathrm{O}_{3}\right.$, and $\left.\mathrm{MgO}\right)$ and carbonates $\left(\mathrm{CaCO}_{3}, \mathrm{MnCO}_{3}, \mathrm{Na}_{2} \mathrm{CO}_{3}\right.$, and $\left.\mathrm{K}_{2} \mathrm{CO}_{3}\right)$. The mixtures were decarbonated at $1000^{\circ} \mathrm{C}$ for two

152 hours and subsequently melted in air at $1450{ }^{\circ} \mathrm{C}$ for six hours. The obtained oxidized glasses were

153 crushed to a fine powder. The synthetic bulk glasses were reduced at the graphite-CO buffer, which is at 154 IW-6.7 at $1450^{\circ} \mathrm{C}$. Specifically, the oxidized glass powders were pressed into graphite crucibles with a 155 diameter of $3 \mathrm{~cm}$ and heights of $5 \mathrm{~cm}$ and suspended on $\mathrm{W}$-Re wires in a gas-mixing furnace. The glasses 156 were reduced at $1450^{\circ} \mathrm{C}$ in pure CO-gas for 24 hours.

\subsection{Sample characterization}

Polished blocks of in situ samples and thin sections of aliquots of the bulk samples were first examined in transmission and reflectance using optical microscopy (Figs.A1,1;2). The samples were then characterized using a JEOL JXA-8530F Hyperprobe electron probe micro analyzer (EPMA) (Institut für Mineralogie, Münster) at a voltage of $15 \mathrm{kV}$, using a beam current of $15 \mathrm{nA}$ (Fig.3; Table 2). Glasses were analyzed using a defocused beam of $5 \mu \mathrm{m}$ diameter. Matrix corrections were made using the $\Phi \rho(z)$ procedure. Natural and synthetic minerals were used as standards: Jadeite $\left(\mathrm{Na}_{2} \mathrm{O}\right)$, SanCarlos olivine $(\mathrm{MgO})$, disthene $\left(\mathrm{Al}_{2} \mathrm{O}_{3}\right)$, hypersthene $\left(\mathrm{SiO}_{2}\right)$, sanidine $\left(\mathrm{K}_{2} \mathrm{O}\right)$, diopside $(\mathrm{CaO})$, fayalite $(\mathrm{FeO})$, rutile $\left(\mathrm{TiO}_{2}\right)$, $166 \mathrm{Cr}_{2} \mathrm{O}_{3}$, and rhodonite (MnO). 
172 was $532 \mathrm{~nm}$ at a spectral resolution of $\sim 7 \mathrm{~cm}^{-1}$ and a spot size of $\sim 2 \mu \mathrm{m}$. Spectra were obtained at a laser

173 power of $1.8 \mathrm{~mW}\left(0.6 \mathrm{~mW} / \mu \mathrm{m}^{2}\right.$ on the sample surface). Since the spectrometer used is not a confocal

174 instrument, for each spectrum, 4 measurements and only 3 seconds acquisition time were accumulated.

175 The final results were background- and baseline-subtracted using a standard optimized routine of the

176 Ocean Optics software.

\section{$178 \quad$ 2.5. Infrared Spectroscopy}

\section{$179 \quad$ 2.5.1. Micro-FTIR Studies of in situ Samples}

To test the spectral homogeneity of the bulk glasses in the spectral range of the MERTIS at the Institute for Geology in Bern. A line of spots was measured across the sample, with a spot size of 183 approximately $5 \mu \mathrm{m}$ (Fig.4).

In situ FTIR microscope analyses were conducted on polished glass samples using a Bruker Hyperion 1000/2000 System at the Hochschule Emden/Leer. We used a $250 \mu \mathrm{m} \times 250 \mu \mathrm{m}$ sized aperture (Fig.5). For analyses requiring higher spatial resolution, a Perkin-Elmer Spotlight-400 FTIR spectrometer at the University of Manchester was used to map samples using an adjoining Focal Plane Array (FPA) mapping unit with a resolution of $6.25 \mu \mathrm{m} \times 6.25 \mu \mathrm{m}$ in the reflectance mode (Fig.5). Spectra for the glass phases were extracted from the mapped area by Principal Component Analysis (PCA) (Martin et al.,

190 2017).One of the spectral features of interest in the spectral range of from $7-14 \mu \mathrm{m}$ is the Christiansen

191 Feature (CF), a reflectance low (or emission high). This feature is important since it is usually observable 192 even in data with low signal to noise ratio. In addition, it is a good proxy for the bulk composition, since 193 the band position shifts with the $\mathrm{SiO}_{2}$ content of the material (Cooper et al., 2002). The Reststrahlen 194 Bands (RB) is the vibrational mode of the structure, characteristically for each mineral and glass phase. 
The Transparency Feature (TF) occurs in spectra of the finest grain size fraction (below $60 \mu \mathrm{m}$ ) and is

196 thus a very good indicator for grain sizes in remote sensing spectra (e.g., Salisbury et al. 1993).

\subsubsection{Diffuse Reflectance of Powdered Bulk Glasses}

For the FTIR diffuse reflectance analyses of the bulk glasses, size fractions smaller $25 \mu \mathrm{m}, 25 \mu \mathrm{m}$

200 to $63 \mu \mathrm{m}, 63 \mu \mathrm{m}$ to $125 \mu \mathrm{m}$, and $125 \mu \mathrm{m}$ to $250 \mu \mathrm{m}$ of the powdered bulk glass material were measured.

201 For diffuse reflectance analyses in the range from $2 \mu \mathrm{m}$ to $20 \mu \mathrm{m}$ we used a Bruker Vertex 70v infrared

202 system with a MCT detector at the IRIS (Infrared and Raman for Interplanetary Spectroscopy) laboratory

203 at the Institut für Planetologie in Münster. Analyses were conducted under low pressure $\left(3 \cdot 10^{-3} \mathrm{bar}\right)$ (Fig.

2045 and 6). For each analysis, 512 scans were integrated to obtain a high signal to noise ratio. To emulate

205 variations in orbital geometry, we obtained spectra with a A513 variable mirror stage. The results in this

206 study were measured used a geometry of $20^{\circ}$ incidence and $30^{\circ}$ emergence angle in order to avoid

207 specular reflectance. The laboratory spectra will be archived in the IRIS laboratory (Hiesinger et al.,

208 2020), and also be available after publication on Mendeley Data under doi: 10.17632/tkcn436c4z.1.

210 3. Results

\subsection{Characterization}

Optical images of particular glass rich samples from Namur and Charlier (2017; list of used

213 samples see Table 1) show mostly homogeneous, glassy patches with only a few crystallization products

214 in the low-Mg glasses (Fig.A1). A few in situ samples (Y124_HMg, Y126_HMg, and Y131HMg) were highly

215 crystalline, so we were using mapping modes for the FTIR analyses to extract the spectral properties of 216 the glass (Fig.1). 
217 Optical images of all bulk glass samples in backscattered electron (BSE) mode (Fig. 2a-d) show generally a

218 homogenous, glassy material. However, fine iron particles in schlieren-like formations occur as a minor

219 component. Additional SEM studies of the bulk glass samples also shows small, usually sub- $\mu \mathrm{m}$ sized

220 particles identified as Fe metal by EDX. They occur also in schlieren-like concentrations, with abundances

221 increasing from the iron poor 181 High-Mg I/ samples to the iron-rich 159 Low-Mg C sample. Fe solubility

222 is a function of $\mathrm{fO}_{2}$. With decreasing $\mathrm{fO}_{2}$, the solubility of Fe decreases and such metal nuggets form.

The bulk samples also exhibit schlieren of fine, dark particles in the optical transmission images

224 (Fig. 2a-d). These are expected contamination from the carbon crucibles used to synthesize the glasses.

225 For quality control, the fine dark particles were analyzed using micro-Raman (Fig. 4). The particles were

226 identified as carbon, characterized by typical bands at $1580 \mathrm{~cm}^{-1}$ as the single Raman active mode of

227 graphite. This corresponds to the mode in the middle of the Brillouin zone with an $\mathrm{E}_{2 \mathrm{~g}}$-symmetrie (Debus,

228 2012). To investigate if the carbon grains affect the spectral properties of the samples, several spots on

229 the surface of a polished sample were analyzed using the surface sensitive ATR (Attenuated Transmission

230 and Reflectance) technique (Fig. 4). Despite variations in the distribution of the metal and carbon grains,

231 the spectra of each spot are identical, overall variation intensities of the strong silicate feature at

$232 \quad 10.7 \mu \mathrm{m}$ is below $1 \%$ absorbance.

Compositional EMPA analyses of the glasses in the in situ samples are listed in Table 1 and

234 illustrated in Fig. 3. Compositions range for $\mathrm{SiO}_{2}$ from 54.7 wt\% (Y122_ICP) to 68.1 wt\% (Y144_SP). MgO

235 ranges from $3.4 \mathrm{wt} \%$ (Y144_SP) to $26.5 \mathrm{wt} \%$ (Y121_HMg). Among the bulk glasses (Table 2; Fig.3), sample

$236159 \mathrm{Low}-\mathrm{Mg} \mathrm{C}$ is the MgO-poorest end member (1.6 wt \%), and has a $\mathrm{SiO}_{2}$ content of $75.7 \mathrm{wt} \%$. Glass 158

237 Low Mg-B has a slightly higher $\mathrm{MgO}$ with $4.7 \mathrm{wt} \%$, and a $\mathrm{SiO}_{2}$ content of $67.3 \mathrm{wt} \%$. Sample $174 \mathrm{Low}-\mathrm{Mg}$

238 A I/ covers an intermediate compositional $\mathrm{MgO}$ range with $9 \mathrm{wt} \%$ and $\mathrm{SiO}_{2}$ at $64.3 \mathrm{wt} \% . \mathrm{Al}_{2} \mathrm{O}_{3}$ shows

239 comparatively little variation in this Mg-poor group (14.3 wt\% - 15.4 wt\%), as does $\mathrm{Na}_{2} \mathrm{O}$ (4.8 wt\% - 6.1

240 wt\%). CaO shows more variation, $1.9-6.8$ wt\%. The 181 High-Mg Glass I/ is the Mg rich endmember 
with 19.0 wt\% $\mathrm{MgO}$, and low $\mathrm{SiO}_{2}(59.3 \mathrm{wt} \%)$ and $\mathrm{Al}_{2} \mathrm{O}_{3}$ (11 wt\%). All other elements are below $1 \mathrm{wt} \%$.

242 Differences to the model starting compositions (Table 2) were difficult to avoid due to the production 243 process, but all samples cover the intended range.

\subsubsection{Micro-FTIR Reflectance Studies of in situ Samples}

The in situ reflectance spectra obtained from glassy spots with micro-FTIR mostly show only a dominating, single RB in the range from $9.3 \mu \mathrm{m}$ to $9.9 \mu \mathrm{m}$ (Fig.5; Table3a). This results from the 'classic'

248 Si-O stretching of silicate-rich glass (King et al., 2004; Speck et al., 2011; Zeng et al., 2019). The other 249 main feature, the CF, falls between $7.8 \mu \mathrm{m}$ and $8.2 \mu \mathrm{m}$. Only a few spectra show more spectral bands:

250 Sample Y124_HMg has additional (weak) bands at $10.1 \mu \mathrm{m}, 10.5 \mu \mathrm{m}, 12.6 \mu \mathrm{m}$, and $13.2 \mu \mathrm{m}$. Spectra for 251 Y126_HMg have similar features at $10.1 \mu \mathrm{m}$, and $10.5 \mu \mathrm{m}$. These are typical forsterite features, 252 indicating incipient crystallization (Lane et al., 2011).

\subsubsection{FTIR Diffuse Reflectance Studies of Bulk Glasses}

All four bulk glass samples exhibit the typical simple spectra of amorphous materials, i.e., one strong RB in the $6 \mu \mathrm{m}$ to $18 \mu \mathrm{m}$ range in the size fractions over $25 \mu \mathrm{m}$ (Fig. 6; Table 3b). Band intensities

257 increase with increasing grain size. At shorter wavelengths (below $7 \mu \mathrm{m}$ ), weak volatile features occur, 258 mostly in the finer size fractions. Typical are water and $\mathrm{CH}_{4}$ bands (e.g., King et al., 2004) at 2.8-2.9 $\mu \mathrm{m}$, $2593.4 \mu \mathrm{m}, 3.5 \mu \mathrm{m}$, and $5.8 \mu \mathrm{m}$ (not shown in figure). Low Mg end member $159 \mathrm{Low}-\mathrm{Mg} C$ (1.6 wt\% MgO) 260 has the RB at 9.2 -9.3 $\mu \mathrm{m}$, and the CF at $7.6-7.7 \mu \mathrm{m}$. The finest size fraction $(0-25 \mu \mathrm{m})$ has the 261 characteristic TF at $11.6 \mu \mathrm{m}$. Sample $158 \mathrm{Low}-\mathrm{Mg} B$ also exhibits low Mg contents (4.7 wt\% MgO). Its CF 262 is at $7.8 \mu \mathrm{m}$, the single $\mathrm{RB}$ is at $9.4 \mu \mathrm{m}$. The TF in the $0-25 \mu \mathrm{m}$ size fraction is at $11.7 \mu \mathrm{m}$. 
Intermediate sample 174 Low Mg A I/ (9 wt\% MgO) has the characteristic features shifted slightly to

264 longer wavelengths: the $\mathrm{CF}$ is at $7.9 \mu \mathrm{m}$, the RB at $9.6 \mu \mathrm{m}$, and the TF is at $11.8 \mu \mathrm{m}$. The Mg-rich

265 endmember 181 High-Mg /l (19.0 wt\% MgO) still shows only bands of amorphous material: the CF is at 8-

$2668.1 \mu \mathrm{m}$ and the broad RB is at $9.8 \mu \mathrm{m}$. The comparatively weak TF is at $11.9 \mu \mathrm{m}$.

\section{4. Discussion}

\subsection{General Chemical Composition and CF}

Of particular interest are correlations between chemical aspects of the glass and the

fundamental spectral features, i.e. the CF and the dominating RB. Since it is difficult to extract quantitative chemical abundances from remote sensing data, it is easier to use elemental ratios (weight \%; Fig. 3), e.g., relative to wt\% Si (Table 1, 2). For the CF, strongest Coefficient of Determination ( $r$

274 squared; $r^{2}$ ) is found for $\mathrm{Mg} / \mathrm{Si}$ with $r^{2}=0.77 . \mathrm{Ca} / \mathrm{Si}$ only has a moderate correlation of $r^{2}=0.33$. K/Si show good correlation with $r^{2}=0.55$. All other elements only have a weak correlation.

\subsection{Bulk and Micro-FTIR Spectra}

Here, we compare the glasses obtained from high pressure laboratory experiments (Namur and 279 Charlier, 2017) analyzed in situ with micro-FTIR with the results of the largest size fraction (125 - 250 $\mu \mathrm{m}$ ) of the bulk glasses, arranged by increasing Mg content from top to bottom (Fig. 5). The spectra of the four powdered bulk glasses agree very well with trends defined by the spectra from micro-FTIR analyses, both regarding the positions of the CFs and the dominating RB, which both shift to longer 


\subsection{Comparison with Earlier Studies}

\subsection{1. $\mathrm{CF}$ and $\mathrm{SiO}_{2}$ content}

Previous studies showed that the chemical composition and spectral parameters are correlated with the bulk $\mathrm{SiO}_{2}$ content and the position of the CF (Fig.7a). By its nature as a reflectance minimum (or emission maximum), the CF is relatively easily identified even in weak or noisy data, and thus is very useful in remote sensing. The powdered bulk glasses from this study follow the typical linear trend observed by earlier studies (Cooper et al., 2002), and also overlap with synthetic glasses with similar compositions from earlier studies (Morlok et al., 2016b; 2017b; 2020a). Glasses from the in situ samples also follow the general trend well and overlap with the synthetic glasses from our earlier studies (Fig.7a).

\subsection{2. $\mathrm{RB}$ and $\mathrm{SiO}_{2}$ Content}

The correlation between glass $\mathrm{SiO}_{2}$ content and the dominating $\mathrm{RB}$ has been shown to be strong for glasses (e.g., Morlok et al., 2017b, 2020a). Similar to the CF, such a single, strong spectral feature is relatively easy to identify in most spectra. Glasses with high and intermediate $\mathrm{SiO}_{2}$ contents follow a linear trend line from 100 to $50 \mathrm{wt} \% \mathrm{SiO}_{2}$ that splits at lower $\mathrm{SiO}_{2}$ (Fig.7b). At lower $\mathrm{SiO}_{2}$ contents, two potential trends are recognizable. A shallow one depicts glass from conventional melting processes. A steeper trend was observed in glasses that underwent vaporization processes (Morlok et al., 2020a and intermediate range and follow the trend established by earlier studies of synthetic glass very well. In a glasses formed in other processes difficult. 
The interconnection of the $\mathrm{SiO}_{4}$ tetrahedrons is a way to describe the degree of polymerization

310 of the phases. This can be done in the form of the SCFM index, which is calculated as

$311 \mathrm{SiO}_{2} /\left(\mathrm{SiO}_{2}+\mathrm{CaO}+\mathrm{FeO}+\mathrm{MgO}\right)$ (Walter and Salisbury, 1989; Salisbury et al., 1997; Cloutis et al., 2002;

312 Cooper et al., 2002) (Fig.7c). While high $\mathrm{SiO}_{2}$ glasses fall near the trend line for earlier, usually crystalline 313 phases (Cooper et al., 2002), samples with intermediate and basaltic compositions plot slightly off the 314 trend line for crystalline terrestrial rocks (Cooper et al., 2002). The results from the micro-FTIR are very 315 similar to those of synthetic glasses from earlier studies (Morlok et al.,2020a and b; Zeng et al., 2019).

316 This indicates a similarity of the synthetic glasses and that the material from the high pressure 317 experiments is generally structurally similar to natural materials.

\subsection{Comparison with the Surface of Mercury}

In this part, we will compare the results from this study with available mid-infrared data from the

321 surface of Mercury. This is an entirely qualitative comparison between band features, in order to see if 322 there is any direct sign of glassy material in the surface spectrum.

Only a few mid-infrared ground-based spectra of Mercury are available (Donaldson-Hanna et al.,

324 2007; Sprague et al., 1994, 1997, 2000, 2002, 2007; Sprague and Roush, 1998; Emery et al., 1998; Cooper

325 et al., 2001). The spectra cover larger surface regions of up to $10^{6} \mathrm{~km}^{2}$. Due to observational limitations,

326 terrestrial spectra of Mercury have only weak spectral contrast and low signal to noise ratio (e.g. Sprague

327 et al., 2007). Therefore, we limit our comparison of the results from this study to a hermean spectrum

328 showing a high signal to noise ratio by the Mid-Infrared Camera (MIRAC) at the Kitt Peak Observatory of 329 a region at about $210-250^{\circ}$ longitude (Sprague et al., 2000). The spectrum for the hermean surface 
(Fig.8; top) was recalculated from reflectance form emissivity and baseline subtracted. It exhibits significant RBs at $9.3 \mu \mathrm{m}, 9.9 \mu \mathrm{m}$, and $11 \mu \mathrm{m}$, a CF is at $8.5 \mu \mathrm{m}$, and a (potential) TF occurs at $12.4 \mu \mathrm{m}$. that of the spectrum of the surface of Mercury $(8.5 \mu \mathrm{m})$, such as samples Y121_ICP-1 $(8.2 \mu \mathrm{m})$ and 181

High-Mg I/ (8-8.1 $\mu \mathrm{m})$. Regarding the band position of the dominating RB in the glass spectra, 181 High$\mathrm{Mg} / \mathrm{l}$ and high $\mathrm{MgO}$ in situ samples, are similar to the $9.9 \mu \mathrm{m}$ feature in the hermean surface spectrum with band positions between 9.8 and $9.9 \mu \mathrm{m}$. The single, dominating RB of $159 \mathrm{Low}-\mathrm{Mg} \mathrm{C}$ at 9.2-9.3 $\mu \mathrm{m}$ has similarities to the $9.3 \mu \mathrm{m}$ band in the hermean spectrum. The TF closest to the $12.4 \mu \mathrm{m}$ band in the Mercury spectrum is that of $181 \mathrm{High}-\mathrm{Mg} / /(11.9 \mu \mathrm{m})$. Thus no individual glass spectrum from this study would reproduce the astronomical spectrum of Mercury. Particularly, crystalline phases are needed in order to provide the strong RB features.

\section{Summary and Conclusions}

We synthesized and characterized size fractions of synthetic analog glasses based on high pressure laboratory studies of the hermean mantle and surface analog rocks. These samples were studied as powders in the mid-infrared $(2-20 \mu \mathrm{m})$. In addition, a series of glassy areas from high pressure petrological laboratory experiments in situ using micro-FTIR (Fig.5).

Results for the powdered bulk glasses with very low $\mathrm{MgO}$ (1.6 wt\% to $19.0 \mathrm{wt} \%$ ) show simple spectra typical for glassy materials: A single, dominant RB between $9.2 \mu \mathrm{m}$ and $9.8 \mu \mathrm{m}$, and a CF between $7.6 \mu \mathrm{m}$ and $8.1 \mu \mathrm{m}$. The TF is located between $11.6 \mu \mathrm{m}$ and $11.9 \mu \mathrm{m}$ (Fig.6). Features for the in 350 situ glass samples with $3.4-26.5 \mathrm{wt} \% \mathrm{MgO}$ range from $7.8 \mu \mathrm{m}$ to $8.2 \mu \mathrm{m}$ for the $\mathrm{CF}$, and $9.3 \mu \mathrm{m}$ to 9.9 $351 \mu \mathrm{m}$ for the RB. Minor crystalline features were found in rare cases at $10.1 \mu \mathrm{m}, 10.5 \mu \mathrm{m}$, and $12.6-12.8$ $352 \mu \mathrm{m}$ (Fig.5), recording the crystallization of forsterite. 
354 and band shape. Furthermore, the synthetic materials from this study show very similar behavior in 355 comparison with earlier studies, when spectral features (CF, RB) are compared to compositional 356 characteristics $\left(\mathrm{SiO}_{2}\right.$ content, SCFM index) (Fig.7a-c). The strongest correlation between the CF or the dominant RB in a spectrum is with $\mathrm{Mg} / \mathrm{Si}$ ratios.

358 Contamination by carbon from the sample cups during sample synthesis as well as metallic iron nuggets 359 probably have no recognizable impact on the spectral properties, since both phases are very minor, and 360 do not exhibit detectable features in the mid-infrared region. Mid-infrared spectra of large areas of the hermean surface show similarities only to some bands 362 of glass investigated here and hermean surface data. This implies that further components will be needed to reproduce the known spectral data from Mercury in a quantitative way. The hermean regolith 364 has up to $80 \%$ crystalline phases (Warrell et al., 2010). So for detailed, quantitative modeling of the 365 hermean surface, further, crystalline components will have to be taken into account (e.g., Martin et al., 366 2017). The same applies to the following MERTIS related studies, where we will mix the glassy material 367 from this study with crystalline phases in order to emulate the composition of the hermean surface 368 regolith. Such mixtures will allow us to obtain spectra of the hermean surface much closer to those 369 expected from MERTIS on BepiColombo. The suitability of the glass synthesized and studied in this work 370 for both spectral comparison with the surface of Mercury as well as for future mixing experiments is 371 confirmed by the similarity to results from earlier studies, and the internal consistency of the data set. 
376 This work was supported by DLR grant 50 QW 1302/1701 in the framework of the BepiColombo mission

377 (A.M.,I.W.,A.N.S.,M.P.R., K.B.)

378 B.C. is a Research Associate of the Belgian Fund for Scientific Research-FNRS and acknowledges support

379 by the FNRS Incentive Grant 31230854.

380 C.R. was supported by a SNF postdoctoral fellowship.

381 K.H.J. was supported by the UK Science and Technology Facilities Council (ST/M001253/1) and the Royal 382 Society (RS/UF140190).

383

384

385

386

387 


\section{References}

397 Benkhoff J., van Casteren J., Hayakawa H., Fujimoto M., Laakso H., Novara M., Ferri P., Middleton H. R., 398 Ziethe R. (2010) BepiColombo---Comprehensive exploration of Mercury: Mission overview and science 399 goals. Planetary and Space Science 58, 2-20.

400 Bishop JL, Pieters CM (1995) Low-temperature and low atmospheric pressure infrared reflectance 401 spectroscopy of Mars soil analog materials. Journal of Geophysical Research: Planets 100(E3):5369-5379 402 doi:10.1029/94JE03331

403 Brunetto R., Lantz C., Ledu D., Baklouti D., Barucci M. A., Beck P., Delauche L., Dionnet Z., Dumas P., 404 Duprat J., Engrand C., Jamme F., Oudayer P., Quirico E., Sandt C., Dartois E. (2014) Ion irradiation of 405 Allende meteorite probed by visible, IR, and Raman spectroscopies. Icarus 237, 278-292.

406 Byrne P. K., Klimczak C., Williams D. A., Hurwitz D. M., Solomon S. C., Head J. W., Preusker F., Oberst 407 J. (2013) An assemblage of lava flow features on Mercury. Journal of Geophysical Research: Planets, 118, $408 \quad 1303-1322$.

409 Charlier B., Grove T.L. and Zuber M.T. (2013) Phase equilibria of ultramafic compositions on Mercury and 410 the origin of the compositional dichotomy. Earth and Planetary Science Letters 363, 50-60.

411 Christensen P.R., Jakosky B.M., Kieffer H.H., Malin M.C., McSween H.Y., Nealson K., Mehall G.L., 412 Silverman S.H., Ferry S., Caplinger M. and Ravine M. (2004) The Thermal Emission Imaging System 413 (THEMIS) for the Mars 2001 Odyssey Mission. Space Sci. Rev. 110, 85-130.

414 Cloutis E.A., Asher P.M., Mertzman S.A. (2002) Spectral reflectance properties of zeolites and remote 415 sensing implications. Journal of Geophysical Research 107, 5067.

416 Cooper B., Potter A., Killen R., Morgan T. (2001) Midinfrared spectra of Mercury. Journal of Geophysical 417 Research 106, E12, 32803-32814. 
418 Cooper B.L., Salisbury J.W., Killen R.M., Potter, A.E. (2002) Midinfrared spectral features of rocks and 419 their powders. Journal of Geophysical Research 107, E4, 5017-5034.

420 Cross W., Iddings J.P., Pirsson L.V. and Washington H.S. (1902) A Quantitative Chemico-Mineralogical

421 Classification and Nomenclature of Igneous Rocks. The Journal of Geology, 10, 555-690.

422 http://dx.doi.org/10.1086/621030

423 Denevi B.W., Ernst C.M., Meyer H.M., Robinson M.S., Murchie S.L., Whitten J.L., Head J.W., Watters T.R., 424 Solomon S.C., Ostrach L.R. et al. (2013) The distribution and origin of smooth plains on Mercury. Journal 425 of Geophysical Research: Planets 118,. 891-907.

426 Donaldson Hanna K. L., Sprague A. L., Kozlowski R. W. H., Boccafolo K., Warell J. (2007) Mercury and the 427 Moon: Initial Findings from Mid-Infrared Spectroscopic Measurements of the Surface. 38th Lunar and 428 Planetary Science Conference, (Lunar and Planetary Science XXXVIII), LPI Contribution No. 1338.

429 DuFresne C.D.M., King P.L., Dyar D., Dalby K.N. (2009) Effect of SiO2, total FeO, Fe3+/Fe2+, and alkali 430 elements in basaltic glasses on mid-infrared spectra. American Mineralogist 94, 1580-1590.

431 Emery J.P., Sprague A.L., Witteborn F.C., Colwell F.C., Kozlowski R.W.H. (1998) Mercury: Thermal 432 Modeling and Mid-infrared (5-12 $\mu \mathrm{m})$ Observations. Icarus 136, 104-123.

433 Goldsten J. O., Rhodes E. A., Boynton W. V., Feldman W. C., Lawrence D. J., Trombka J. I., Smith D. 434 M., Evans L. G., White J., Madden N. W., Berg P. C., Murphy G. A., Gurnee R. S., Strohbehn K., 435 Williams B. D., Schaefer E. D., Monaco C. A., Cork C. P., Del Eckels J., Miller W. O. (2007) Space 436 Science Reviews 131, 339-391.

437 Goudge T.A., Head J.W., Kerber L., Blewett D.T., Denevi B.W., Domingue D.L., Gillis-Davis J.J., Gwinner K., 438 Helbert J., Holsclaw G.M. et al. (2014) Global inventory and characterization of pyroclastic deposits on 439 Mercury: New insights into pyroclastic activity from MESSENGER orbital data. Journal of Geophysical $440 \quad$ Research: Planets 119, 635-658. 
441 Hiesinger H., Helbert J., Mertis Co-I Team (2010) The Mercury Radiometer and Thermal Infrared

442 Spectrometer (MERTIS) for the BepiColombo mission. Planetary and Space Science 58, 144-165.

443 Hiesinger H., Helbert J., Alemanno G., Bauch K.E., D’Amore M., Maturilli A., Morlok A., Reitze M.P.,

444 Stangarone C., Stojic A.N., Varatharajan I., Weber I. (2020) Studying the Composition and Mineralogy of

445 the Hermean Surface with the Mercury Radiometer and Thermal Infrared Spectrometer (MERTIS) for the

446 BepiColombo Mission: An Update. Space Science Reviews (accepted)

447 Hörz F., Cintala M. (1997) Impact experiments related to the evolution of planetary regoliths. Meteoritics

448 \& Planetary Science 32, 179-209

449 Izenberg N. R., Klima R. L., Murchie S. L., Blewett D. T., Holsclaw G. M., McClintock W. E., Malaret E.,

450 Mauceri C., Vilas F., Sprague A. L., Helbert J., Domingue D. L., Head J. W., Goudge T. A., Solomon S.

451 C., Hibbitts C. A., Dyar M. D. (2014) The low-iron, reduced surface of Mercury as seen in spectral

452 reflectance by MESSENGER. Icarus 228, 364-374.

453 Kerber L., Head J.W., Blewett D.T., Solomon S.C., Wilson L., Murchie S.L., Robinson M.S., Denevi B.W. and

454 Domingue D.L. (2011) The global distribution of pyroclastic deposits on Mercury: The view from

455 MESSENGER flybys 1-3. Planetary and Space Science 59, 1895-1909.

456 P.L. King, M.S. Ramsey, P.F. McMillan, G. Swayze5 (2004) CHAPTER 3. LABORATORY FOURIER

457 TRANSFORM INFRARED SPECTROSCOPY METHODS FOR GEOLOGIC SAMPLES. In: Laboratory Fourier

458 transform infrared spectroscopy methods for geologic samples.

459 Lane M. D., Glotch T. D., Dyar M. D., Pieters C. M., Klima R., Hiroi T., Bishop J. L., Sunshine J. (2011)

460 Midinfrared spectroscopy of synthetic olivines: Thermal emission, specular and diffuse reflectance, and

461 attenuated total reflectance studies of forsterite to fayalite. Journal of Geophysical Research 116, CitelD

462 E08010. 
463 Lee R.J., King P.L., Ramsey M.S. (2010) Spectral analysis of synthetic quartzofeldspathic glasses using 464 laboratory thermal infrared spectroscopy. Journal of Geophysical review 115, B06202.

465 Martin Dayl J. P., Pernet-Fisher John F., Joy Katherine H., Wogelius Roy A., Morlok Andreas, Hiesinger 466 Harald (2017) Investigating the shock histories of lunar meteorites Miller Range 090034, 090070, and 467090075 using petrography, geochemistry, and micro-FTIR spectroscopy. Meteoritics \& Planetary Science $468 \quad 52,1103-1124$

469 McClintock W.E., Lankton M.R. (2007) The Mercury Atmospheric and Surface Composition Spectrometer 470 for the MESSENGER Mission. Space Science Reviews 131, 481-521.

471 Morlok A., Stojic A., Dittmar I., Hiesinger H., Tiedeken M., Sohn M., Weber I., Helbert J. (2016a) Mid-

472 infrared spectroscopy of impactites from the Nördlinger Ries impact crater. Icarus 264, 352-368.

473 Morlok A., Stojic A., Weber I., Hiesinger H., Zanetti M., Helbert J. (2016b) Mid-infrared bi-directional 474 reflectance spectroscopy of impact melt glasses and tektites. Icarus 278, 162-179.

475 Morlok A., Bischoff A., Patzek M., Sohn M., Hiesinger H. (2017a) Chelyabinsk - a rock with many different 476 (stony) faces: An infrared study. Icarus 284, 431-442.

477 Morlok Andreas, Klemme Stephan, Weber Iris, Stojic Aleksandra N., Sohn Martin, Hiesinger Harald 478 (2017b) IR spectroscopy of synthetic glasses with Mercury surface composition: Analogs for remote 479 sensing. Icarus, Volume 296, 123-138.

480 Morlok A., Klemme S., Weber Iris. Stojic A., Sohn M., Hiesinger H., Helbert, J. (2020a) Mid-infrared 481 spectroscopy of planetary analogs: A database for planetary remote sensing. Icarus 324, 86-103.

482 Morlok A., Hamann C., Martin D., Weber I., Joy K. H., Hiesinger H., Wogelius R., Stojic A.N., Helbert J. 483 (2020b) Mid-infrared spectroscopy of laser-produced basalt melts for remote sensing application. Icarus $484335,113410$. 
485

486

487

488

489

490

491

492

493

494

495

496

497

498

Murchie S. L., Klima R. L., Denevi B. W., Ernst C. M., Keller M. R., Domingue D. L., Blewett D. T., Chabot N. L., Hash C. D., Malaret E., Izenberg N. R., Vilas F., Nittler L. R., Gillis-Davis J. J., Head J. W., Solomon S. C. (2015) Orbital multispectral mapping of Mercury with the MESSENGER Mercury Dual Imaging System: Evidence for the origins of plains units and low-reflectance material. Icarus 254, 287305.

Namur O., Collinet M., Charlier B., Grove T. L., Holtz F., McCammon C. (2016) Melting processes and mantle sources of lavas on Mercury. Earth and Planetary Science Letters 439, 117-128.

Namur O., Charlier B. (2017) Silicate Mineralogy at the Surface of Mercury. Nature Geoscience 10, 9-13.

Nittler Larry R., Starr Richard D., Weider Shoshana Z., McCoy Timothy J., Boynton William V., Ebel Denton S., Ernst Carolyn M., Evans Larry G., Goldsten John O., Hamara David K. et al. (2011) The Major-Element Composition of Mercury's Surface from MESSENGER X-ray Spectrometry. Science 333, 1847.

Nittler L.R., Frank E.A., Weider S.Z., Crapster-Pregont E., Vorburger A., Starr R.D. and Solomon S.C. (2020)

Global major-element maps of Mercury from four years of MESSENGER X-Ray Spectrometer observations. Icarus 345, 113716.

Peplowski P.N., Lawrence D.J., Feldman W.C., Goldsten J.O., Bazell D., Evans L.G., Head J.W., Nittler L.R., Solomon S.C., Weider S.Z., 2015. Geochemical terranes of Mercury's northern hemisphere as revealed by MESSENGER neutron measurements. Icarus 253, 346-363.

Peplowski P.N., Stockstill-Cahill K. (2019) Analytical Identification and Characterization of the Major Geochemical Terranes of Mercury's Northern Hemisphere. Journal of Geophysical Research: Planets, $124,2414-2429$.

Rothery D.A., Massironi M., Alemanno G., Barraud O., Besse S., Bott N., Brunetto R., Bunce E. Byrne P., Capaccioni F. et al. (2020) Rationale for BepiColombo Studies of Mercury's Surface and Composition. Space Science Reviews 216, .66 
508 Salisbury J.W. (1993) Mid-Infrared Spectroscopy: Laboratory Data. In: Remote Geochemical Analysis:

509 Elemental and Mineralogical Composition, Eds: C.M. Pieters and P.A.J. Englert. Cambridge University

510 Press.

511 Salisbury J.W., Basu A., Fischer E.M. (1997) Thermal Infrared Spectra of Lunar Soils. Icarus 130, 125-139.

512 Schlemm C. E., Starr R. D., Ho G. C., Bechtold K. E., Hamilton S. A., Boldt J. D., Boynton W. V., Bradley

513 W., Fraeman M. E., Gold R. E., Goldsten J. O., Hayes J. R., Jaskulek S. E., Rossano E., Rumpf R. A.,

514 Schaefer E. D., Strohbehn K., Shelton R. G., Thompson R. E., Trombka J. I. Williams B. D. (2007) Space

515 Science Reviews 131, 393-415.

516 Solomon S.C., Nittler L.R. and Anderson B. (2018) Mercury: The View after MESSENGER. Cambridge

517 University Press, Cambridge, 566 p.

518 Speck A.K., Whittington, A.G. Hofmeister, A.M., 2011. Disordered silicates in space: A study of laboratory

519 spectra of "amorphous" silicates. Astrophysical Journal 740, 1-17.

520 Sprague AL, Witterborn FC, Kozlowski RW, Cruikshank DP, Bartholomew MJ, Graps AL (1992) The Moon:

521 Mid-infrared (7.5- to 11.4- $\mu \mathrm{m}$ ) spectroscopy of selected regions. Icarus 100(1):73-84

522 doi:https://doi.org/10.1016/0019-1035(92)90019-4

523 Sprague AL, Kozlowski RWH, Witteborn FC, Cruikshank DP, Wooden DH (1994) Mercury: Evidence for

524 anorthosite and basalt from mid-infrared (7.3-13.5 $\mu \mathrm{m})$ spectroscopy. Icarus 109(1):156-167

525 Sprague AL, Nash DB, Witteborn FC, Cruikshank DP (1997) Mercury's feldspar connection mid-ir

526 measurements suggest plagioclase. Advances in Space Research 19(10):1507-1510

527 doi:https://doi.org/10.1016/S0273-1177(97)00363-3

528 Sprague A. L. and Roush T. L. (1998). Comparison of laboratory emission spectra with Mercury telescopic 529 data. Icarus 133,174-183. 
530 Sprague A., Deutsch L. K., Hora J., Fazio G. G., Ludwig B., Emery J., and Hoffmann W. F. (2000). Mid-

531 infrared (8.1- $12.5 \mu \mathrm{m})$ imaging of Mercury. Icarus 147, 421-432.

532 Sprague A.L., Emery J.P., Donaldson K.L., Russell R.W., Lynch D.K., Mazuk A.L. (2002) Mercury: Mid-

533 infrared (3-13.5 $\mu \mathrm{m})$ observations show heterogeneous composition, presence of intermediate and basic

534 soil types, and pyroxene. Meteoritics\&Planetary Science 37, 1255-1268.

535 Sprague A., Warell J., Cremonese G., Langevin Y., Helbert J., Wurz P., Veselovsky I., Orsini S. and Milillo A.

536 (2007) Mercury's Surface Composition and Character as Measured by Ground-Based Observations. Space

537 Sci. Rev. 132, 399-431.

538 Stojic A.N., Morlok A., Tollan P., Kohout T., Hermann J., Weber I., Moreau J.G., Hiesinger H., Sohn M.,

539 Reitze M.P., bauch K.E., Helbert J. (2020) A shock recovery experiment and its implications for Mercury's

540 surface: The effect of high pressure on porous olivine powder as a regolith analog. Icarus, under Review

541 Thomas R. J., Rothery, D. A., Conway, S. J., Anand M. (2014) Hollows on Mercury: Materials and

542 mechanisms involved in their formation. Icarus 229, 221-235.

543 Vander Kaaden K. E., McCubbin F. M., Nittler L. R., Peplowski P. N., Weider S. Z., Frank E. A., McCoy T.

544 (2016) Geochemistry, Mineralogy, and Petrology of Boninitic and Komatiitic Rocks on the Mercurian

545 Surface: Insights into the Mercurian Mantle. Icarus 285, 155-168.

546 Vilas F. (1998) Surface composition of Mercury from reflectance spectrophotometry. In: Mercury (A89-

54743751 19-91). Tucson, AZ, University of Arizona Press, 1988, p. 59-76.

548 Walter L.S., Salisbury J.W. (1989) Spectral characterization of igneous rocks in the 8- to 12-micron region. 549 Journal of Geophysical Research 94, 9203-9213.

550 Warrell J., Sprague A., Kozlowski R., Rothery R.A., Lewis N., Helbert J., Cloutis E. (2010) Icarus 209, 138 551163. 
552 Weber I., Morlok A., Bischoff A., Hiesinger H., Ward D., Joy K. H., Crowther S. A., Jastrzebski N. D.,

553 Gilmour J. D., Clay P. L., Wogelius R. A., Greenwood R. C., Franchi I. A., Münker C. (2016) Cosmochemical

554 and spectroscopic properties of Northwest Africa 7325-A consortium study. Meteoritics \& Planetary

555 Science 51, 3-30.

556 Weber I., Stojic A. N., Morlok A., Reitze M. P., Markus K., Hiesinger H., Pavlov S. G., Wirth R., Schreiber A., 557 Sohn M., Hübers H.-W., Helbert J. (2020) Space weathering by simulated micrometeorite bombardment 558 on natural olivine and pyroxene: A coordinated IR and TEM study. Earth and Planetary Science Letters $559530,115884$.

560 Weber I., Reitze M.P., Heeger M., Adolphs T., Morlok A., Stojic A.N., Hiesinger H., Bauch K.E., Arlinghaus 561 H.F., Helbert J. (submitted) Simulation of space weathering on mineral mixtures for remote sensing. 562 Earth and Planetary Science Letters, submitted.

563 Weider Shoshana Z., Nittler Larry R., Starr Richard D., Crapster-Pregont Ellen, Peplowski Patrick N., 564 Denevi Brett W., Head James W., Byrne Paul K., Hauck Steven A., Ebel Denton S., Solomon Sean C., 565 (2015). Evidence for geochemical terranes on Mercury: Global mapping of major elements with 566 MESSENGER's X-Ray Spectrometer. Earth and Planetary Science Letters 416, 109-120.

567 Weitz C. M., Rutherford M. J., Head J. W. (1997) Oxidation states and ascent history of the Apollo 17 568 volcanic beads as inferred from metal-glass equilibria. Geochimica et Cosmochimica Acta 61, 2765-2775.

569 Zeng X., Li X., Martin D., Tang H., Yu W., Liu J., Wang S. (2019) Micro-FTIR Spectroscopy of Lunar 570 Pyroclastic and Impact Glasses as a New Diagnostic Tool to Discern Them. Journal of Geophysical 571 Research: Planets 124, 3267-3282. 
575 Figure Appendix A1. Optical images of polished blocks from the in situ samples used in the Micro-FTIR 576 studies (white rectangle $=256 \mu \mathrm{m} \times 250 \mu \mathrm{m}$ ). The samples are ordered by decreasing Mg content of the 577 glass (Table 1). Most areas analyzed are homogeneous glass areas, with brighter inclusions being 578 crystallized phases. $S P=S m o o t h$ Plains, $H M g=H i g h$ Mg-Region, $H M g-N V P=H i g h-M g$ Northern Volcanic 579 Plains, IcP=Inter Crater Plains.

580 Figure 1 Samples used for micro-FTIR studies. Here whole areas were scanned (red boxes) and the 581 spectral properties extracted (marked in the colored spectral map). SP=Smooth Plains, $H M g=H i g h$ Mg582 Region, $H M g-N V P=$ High-Mg Northern Volcanic Plains, IcP=Inter Crater Plains.

583 Figure 2. Optical images of polished blocks from the samples used for the powdered bulk glass studies.

584 (left) optical transmission images. The silicate part of the material is very homogeneous glass with no 585 larger crystals. However small particles are visible, presumably carbon bits of the sample containers.

586 (center and right) Backscattered electron images. Bright particles are metallic iron, enlarged image in the 587 center show areas of higher density of these grains. Abundances of the metal grains decreases with with 588 increasing Mg contents (top to bottom),

589 Figure 3. Chemical composition of synthetic glasses used in this study (Electron Microprobe Data, weight\%). Circles: In situ samples, Crosses: Bulk Samples, Squares: Data for composition of geochemical terranes on Mercury (vander Kaaden et al., 2017).

592 Figure 4 (left)Optical image of test sample with high abundance of fine-grained carbon particles from the 593 containments. Insert shows Raman spectrum of representative particles, confirming them as graphite.

594 (right) Optical image of polished block from sample 174 Low-Mg A II. White circles show spots from 595 which ATR spectra were taken (left to right, top to bottom), which are shown as insert. Despite varying 596 abundance of fine-grained graphite particles, the spectra show only very minor variations in intensity. 
Figure 5: Comparison of spectra from glassy spots in in situ sample measurements with micro-FTIR (black spectra) to the $125-250 \mu \mathrm{m}$ fraction of the bulk glass powder spectra (grey). Spectra are off-set by a constant value, and for a better comparison of data from different techniques, normalized to the same intensity based on the CF (lowest reflectance) and the strongest RB (point of maximum reflectance).

Vertical lines show the position of the Christiansen Feature (CF) and Reststrahlen Band (RB). Samples are ordered with increasing $\mathrm{Mg}$ content from top to bottom. SP=Smooth Plains, $\mathrm{HMg}=$ High Mg-Region, $\mathrm{HMg}$ $N V P=$ High-Mg Northern Volcanic Plains, IcP=Inter Crater Plains.

Figure 6: Reflectance spectra of powdered bulk glass size fractions 0-25 $\mu \mathrm{m}, 25-63 \mu \mathrm{m}, 63-125 \mu \mathrm{m}$, and 125-250 $\mu \mathrm{m}$ (in $\mu \mathrm{m}$ ). $\mathrm{CF}=$ Christiansen Feature, a reflectance low, $\mathrm{RB}=$ Restrahlenband, $\mathrm{TF}=$ Transparences Feature characteristic for the finest size fraction. All features show a shift to longer wavelengths with increasing Mg content.

Figure 7(a): Comparison of $\mathrm{SiO}_{2}$ contents and the position of the CF. Results of earlier studies fall on a linear trend line, confirming the observation of Cooper et al. (2002). Results of this study also plot along the trend line. (b) Comparison of $\mathrm{SiO}_{2}$ content with the position of the single $\mathrm{RB}$ of the glasses. Results from earlier studies show a basically linear trend from high $\mathrm{SiO}_{2}$ contents to $\sim 50 \mathrm{wt} \% \mathrm{SiO}_{2}$. At lower $\mathrm{SiO}_{2}$ two possible trends are forming, one continuing the trend line, the other following a shallower trend.

613 The results for glasses in this study follow the main trend line. (c) Comparison of the SCFM index $614\left(\mathrm{SiO}_{2} /\left(\mathrm{SiO}_{2}+\mathrm{CaO}+\mathrm{FeO}+\mathrm{MgO}\right)\right)$ (Walter and Salisbury, 1989; Salisbury et al., 1997; Cooper et al., 2002;

615 Cloutis et al., 2002) to the CF band position. With increasing mafic composition, glasses tend to diverge 616 slightly from the trend line for terrestrial rocks (Cooper et al., 2002). Again, the result for the synthetic 617 glasses from this study follow earlier trends very well.

618 Figure 8. Comparison of a ground-based, base-lined spectrum of the surface of Mercury (Sprague et al., 619 2000) to the most similar spectra from this study (in $\mu \mathrm{m}$ ). Spectra are off-set by a constant value, and for 
621 (lowest reflectance) and the strongest RB (point of maximum reflectance). The large grain fraction (125-

$622250 \mu \mathrm{m})$ of Mg-poor end member $159 \mathrm{Low}-\mathrm{Mg} \mathrm{C}(1.6 \mathrm{wt} \% \mathrm{MgO})$ has a RB similar to the $9.3 \mu \mathrm{m}$ feature

623 on the hermean surface. The $125-250 \mu \mathrm{m}$ fraction of Mg-rich $181 \mathrm{High}-\mathrm{Mg} / \mathrm{l}(19.0 \mathrm{wt} \% \mathrm{MgO})$ has a

624 feature similar to the $9.9 \mu \mathrm{m}$ band in the astronomical spectrum Both CF and TF show clear differences.

625

626

627

628

629

630

631

632

633

634

635

636

637

638

639

640 


\begin{tabular}{|c|c|c|c|c|c|c|c|c|c|}
\hline & Y144_SP & Y143_SP & $\begin{array}{l}\text { Y131_- } \\
\text { HMg }\end{array}$ & $\begin{array}{l}\text { Y131_ } \\
\text { LMg-NVP }\end{array}$ & $\begin{array}{l}\text { Y140_ } \\
\text { HMg-NVP }\end{array}$ & $\begin{array}{l}\text { Y140_ } \\
\text { SP }\end{array}$ & $\begin{array}{l}\text { Y121_ } \\
\text { LMg-NVP }\end{array}$ & $\begin{array}{l}\mathrm{Y} 133 \\
\mathrm{SP}\end{array}$ & $\begin{array}{l}\text { Y126 } \\
\text { ICP }\end{array}$ \\
\hline $\mathrm{SiO}_{2}$ & 68.09 & 66.12 & 66.14 & 65.94 & 65.25 & 62.06 & 62.25 & 59.22 & 58.40 \\
\hline $\mathrm{TiO}_{2}$ & 0.51 & 0.02 & 0.35 & 0.26 & 0.04 & 0.09 & 0.38 & 0.38 & 0.33 \\
\hline $\mathrm{Al}_{2} \mathrm{O}_{3}$ & 15.72 & 15.48 & 15.57 & 15.67 & 15.21 & 17.09 & 14.13 & 15.91 & 16.33 \\
\hline $\mathrm{FeO}$ & 0.13 & 0.06 & 0.25 & 0.19 & 0.03 & 0.10 & 0.14 & 0.14 & 0.08 \\
\hline Mno & 0.20 & 0.04 & 0.13 & 0.19 & 0.07 & 0.00 & 0.20 & 0.00 & 0.07 \\
\hline MgO & 3.37 & 5.17 & 5.22 & 5.35 & 6.68 & 7.27 & 10.18 & 11.12 & 12.18 \\
\hline $\mathrm{CaO}$ & 3.65 & 5.69 & 5.30 & 5.27 & 6.64 & 7.46 & 5.69 & 7.51 & 7.27 \\
\hline $\mathrm{Na}_{2} \mathrm{O}$ & 7.45 & 7.50 & 6.72 & 7.16 & 5.87 & 5.24 & 6.17 & 5.31 & 4.88 \\
\hline \multirow[t]{2}{*}{$\mathrm{K}_{2} \mathrm{O}$} & 0.20 & 0.16 & 0.22 & 0.21 & 0.14 & 0.09 & 0.16 & 0.11 & 0.09 \\
\hline & 99.32 & 100.24 & 99.90 & 100.24 & 99.93 & 99.40 & 99.30 & 99.70 & 99.63 \\
\hline $\mathrm{T}\left({ }^{\circ} \mathrm{C}\right)$ & 1170 & 1210 & 1220 & 1220 & 1250 & 1250 & 1480 & 1360 & 1320 \\
\hline $\mathrm{P}(\mathrm{GPa})$ & 0.1 & 0.1 & 0.1 & 0.1 & 0.1 & 0.1 & 0.1 & 0.1 & 0.1 \\
\hline Time (h) & 108 & 96 & 72 & 72 & 69 & 69 & 4 & 48 & 70 \\
\hline$\Delta \mathrm{IW}$ & -6.2 & -5.6 & -5.7 & -5.9 & -5.0 & -4.9 & -4.8 & - & -5.6 \\
\hline Glass & 0.42 & 0.54 & 0.42 & 0.87 & 0.73 & 0.91 & 1 & 1 & 0.79 \\
\hline Unit & $\begin{array}{l}\text { Smooth } \\
\text { Plains }\end{array}$ & $\begin{array}{l}\text { Smooth } \\
\text { Plains }\end{array}$ & $\begin{array}{l}\text { High-Mg } \\
\text { Province }\end{array}$ & $\begin{array}{l}\text { Low-Mg } \\
\text { Northern } \\
\text { Volc. Plains }\end{array}$ & $\begin{array}{l}\text { High-Mg } \\
\text { Northern } \\
\text { Volc. Plains }\end{array}$ & $\begin{array}{l}\text { Smooth } \\
\text { Plains }\end{array}$ & $\begin{array}{l}\text { Low-Mg } \\
\text { Northern } \\
\text { Volc. Plains }\end{array}$ & $\begin{array}{l}\text { Smooth } \\
\text { Plains }\end{array}$ & $\begin{array}{l}\text { Inter } \\
\text { Crater } \\
\text { Plains }\end{array}$ \\
\hline
\end{tabular}

641

642

\begin{tabular}{|c|c|c|c|c|c|c|c|c|c|}
\hline & C580_NVP & $\begin{array}{l}\text { Y126_ } \\
\text { HMg }\end{array}$ & $\begin{array}{l}\text { Y133_- } \\
\text { HMg-NVP }\end{array}$ & $\begin{array}{l}\text { Y124_- } \\
\text { HMg }\end{array}$ & $\begin{array}{l}\text { Y123_ } \\
\text { ICP }\end{array}$ & $\begin{array}{l}\text { Y123_- } \\
\text { HMg }\end{array}$ & $\begin{array}{l}\text { Y121_- } \\
\text { ICP }\end{array}$ & $\begin{array}{l}\text { Y122_ } \\
\text { ICP }\end{array}$ & $\begin{array}{l}\text { Y121_- } \\
\text { HMg }\end{array}$ \\
\hline $\mathrm{SiO}_{2}$ & 57.47 & 59.96 & 60.13 & 59.51 & 56.44 & 57.45 & 55.53 & 54.69 & 55.22 \\
\hline $\mathrm{TiO}_{2}$ & 0.40 & 0.56 & 0.62 & 0.45 & 0.29 & 0.48 & 0.25 & 0.27 & 0.39 \\
\hline $\mathrm{Al}_{2} \mathrm{O}_{3}$ & 14.28 & 10.56 & 12.52 & 9.87 & 14.40 & 9.00 & 12.37 & 12.66 & 6.97 \\
\hline $\mathrm{FeO}$ & 0.01 & 0.18 & 0.14 & 0.15 & 0.06 & 0.05 & 0.23 & 0.07 & 0.15 \\
\hline MnO & 0.13 & 0.24 & 0.21 & 0.20 & 0.03 & 0.24 & 0.09 & 0.10 & 0.25 \\
\hline MgO & 12.90 & 14.44 & 15.41 & 16.33 & 17.74 & 20.34 & 21.51 & 21.73 & 26.51 \\
\hline $\mathrm{CaO}$ & 5.87 & 10.30 & 6.54 & 9.19 & 5.87 & 8.86 & 5.40 & 5.75 & 7.06 \\
\hline $\mathrm{Na}_{2} \mathrm{O}$ & 7.01 & 3.60 & 3.99 & 3.97 & 4.74 & 3.40 & 4.14 & 4.02 & 3.16 \\
\hline \multirow[t]{2}{*}{$\mathrm{K}_{2} \mathrm{O}$} & 0.17 & 0.11 & 0.11 & 0.10 & 0.08 & 0.07 & 0.05 & 0.07 & 0.07 \\
\hline & 98.24 & 99.95 & 99.67 & 99.77 & 99.65 & 99.89 & 99.57 & 99.36 & 99.78 \\
\hline $\mathrm{T}\left({ }^{\circ} \mathrm{C}\right)$ & 1450 & 1320 & 1360 & 1360 & 1400 & 1400 & 1480 & 1440 & 1480 \\
\hline$P(G P a)$ & 0.15 & 0.1 & 0.1 & 0.1 & 0.1 & 0.1 & 0.1 & 0.1 & 0.1 \\
\hline $\begin{array}{l}\text { Time } \\
\text { (h) }\end{array}$ & 6 & 70 & 48 & 45 & 52 & 52 & 4 & 26 & 4 \\
\hline$\Delta \mathrm{IW}$ & -6.4 & -5.4 & - & -5.6 & -5.8 & -6.1 & -4.8 & -4.8 & -4.7 \\
\hline Glass & 0.98 & 0.71 & 0.97 & 0.75 & 0.90 & 0.83 & 1 & 1 & 1 \\
\hline Unit & $\begin{array}{l}\text { Northern } \\
\text { Volcanic } \\
\text { Plains }\end{array}$ & $\begin{array}{l}\text { High-Mg } \\
\text { Province }\end{array}$ & $\begin{array}{l}\text { High-Mg } \\
\text { Northern } \\
\text { Volc. Plains }\end{array}$ & $\begin{array}{l}\text { High-Mg } \\
\text { Province }\end{array}$ & $\begin{array}{l}\text { Inter Crater } \\
\text { Plains }\end{array}$ & $\begin{array}{l}\text { High-Mg } \\
\text { Province }\end{array}$ & $\begin{array}{l}\text { Inter Crater } \\
\text { Plains }\end{array}$ & $\begin{array}{l}\text { Inter } \\
\text { Crater } \\
\text { Plains }\end{array}$ & $\begin{array}{l}\text { High-Mg } \\
\text { Province }\end{array}$ \\
\hline
\end{tabular}

643 Table 1: Chemical composition (in wt\%) of the glass phases analyzed in in situ samples using micro-FTIR.

$644 \mathrm{SP}=$ Smooth Plains, HMg=High Mg-Region, HMg-NVP=High-Mg Northern Volcanic Plains, IcP=Inter Crater 645 Plains, LMg-NVP=Low Mg Northern Volcanic Plains. Source: Namur and Charlier, 2017. [R1-1] 


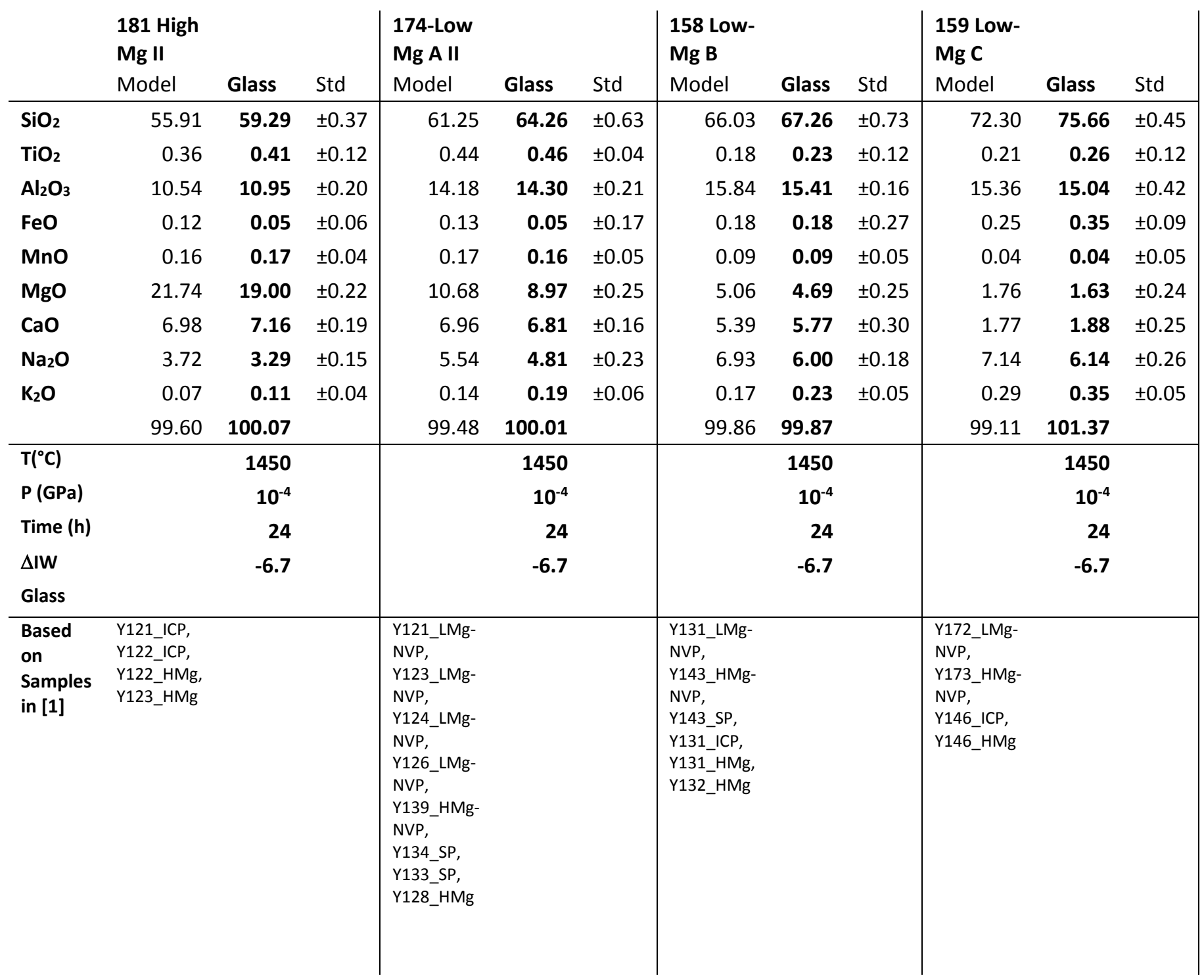

647 Table 2: Chemical composition in wt\% of the synthetic bulk glasses used for the size fractions of the powder studies, arranged by increasing $\mathrm{SiO}_{2}$ content. In wt\%. Model: Composition calculated for the starting mixture based on results from Namur and Charlier (2017) [1]. Glass: Chemical composition of the synthesized glass (in wt\%). Std: Standard Deviation. SP=Smooth Plains, HMg=High Mg-Region, HMgNVP=High-Mg Northern Volcanic Plains, IcP=Inter Crater Plains, LMg-NVP=Low Mg Northern Volcanic Plains. Source: Namur and Charlier, 2017 


\begin{tabular}{|c|c|c|c|c|c|c|c|}
\hline Sample & $\mathrm{CF}$ & & RB & & & & \\
\hline & $\mu \mathrm{m}$ & $\mu \mathrm{m}$ & $\mu \mathrm{m}$ & $\mu \mathrm{m}$ & $\mu \mathrm{m}$ & $\mu \mathrm{m}$ & $\mu \mathrm{m}$ \\
\hline Y144_SP & 7.76 & & 9.47 & & & & \\
\hline Y143_SP & 7.79 & & 9.61 & & & & \\
\hline Y131_HMg & 7.96 & & 9.45 & & & & \\
\hline Y131_HMg & 7.87 & & 9.33 & & & 12.66 & \\
\hline Y131_LMg & 7.91 & & 9.62 & & & & \\
\hline Y131_LMg & 7.89 & & 9.62 & & & & \\
\hline Y140_HMg-NVP & 7.91 & & 9.69 & & & & \\
\hline Y140_SP & 7.8 & & 9.53 & & & & \\
\hline Y121_LMg-NVP & 7.94 & & 9.71 & & & & \\
\hline Y133_SP & 7.99 & & 9.81 & & & & \\
\hline Y126_ICP & 7.93 & & 9.79 & & & & \\
\hline C580A_NVP & 8.05 & & 9.81 & & & & \\
\hline Y126_HMg & 8.02 & & 9.8 & & 10.51 & 12.83 & \\
\hline Y126_HMg & 8 & & 9.76 & 10.1 & 10.51 & & \\
\hline Y133_HMg-NVP & 8.06 & & 9.86 & & & & \\
\hline Y124_HMg & 7.97 & 9.69 & 9.84 & 10.12 & 10.53 & 12.63 & 13.23 \\
\hline Y123_ICP & 8.03 & & 9.81 & & & & \\
\hline Y123_HMg & 8.1 & & 9.88 & & & & \\
\hline Y121_ICP & 8.23 & & 9.93 & & & & \\
\hline Y122_ICP & 8.12 & & 9.94 & & & & \\
\hline Y121_HMg & 8.1 & & 9.94 & & & & \\
\hline
\end{tabular}

658 Table 3a: Band positions (in $\mu \mathrm{m}$ ) of glasses in situ samples on polished blocks. CF = Christiansen Feature; $659 \mathrm{RB}=$ Strongest Reststrahlenband; $\mathrm{TF}=$ Transparency Feature. SP=Smooth Plains, HMg=High Mg-Region, $660 \quad H M g-N V P=$ High-Mg Northern Volcanic Plains, IcP=Inter Crater Plains. 


\begin{tabular}{|c|c|c|c|c|c|c|c|c|}
\hline \multicolumn{6}{|l|}{ Sample } & \multirow{2}{*}{$\begin{array}{l}\text { CF } \\
\mu \mathrm{m}\end{array}$} & \multirow{2}{*}{$\begin{array}{l}\text { RB } \\
\mu \mathrm{m}\end{array}$} & \multirow{2}{*}{$\begin{array}{l}\mathrm{TF} \\
\mu \mathrm{m}\end{array}$} \\
\hline $\begin{array}{l}181 \text { High Mg } \\
\text { II }\end{array}$ & $\mu \mathrm{m}$ & $\mu \mathrm{m}$ & $\mu \mathrm{m}$ & $\mu \mathrm{m}$ & $\mu \mathrm{m}$ & & & \\
\hline $0-25 \mu \mathrm{m}$ & 2.95 & 3.38 & 3.42 & 3.5 & & 8.07 & 9.81 & 11.91 \\
\hline $25-63 \mu \mathrm{m}$ & 2.95 & 3.38 & 3.41 & 3.5 & & 8.07 & 9.8 & \\
\hline $63-125 \mu \mathrm{m}$ & 2.94 & 3.38 & 3.41 & 3.5 & & 8.06 & 9.78 & \\
\hline $125-250 \mu \mathrm{m}$ & 2.93 & 3.38 & 3.41 & & & 8.03 & 9.8 & \\
\hline \multicolumn{9}{|l|}{174 Low-Mg } \\
\hline \multicolumn{9}{|l|}{ A II } \\
\hline $0-25 \mu \mathrm{m}$ & 2.95 & 3.37 & 3.41 & 3.5 & & 7.89 & 9.58 & 11.77 \\
\hline $25-63 \mu \mathrm{m}$ & 2.94 & 3.37 & 3.41 & & & 7.87 & 9.57 & \\
\hline $63-125 \mu \mathrm{m}$ & 2.93 & 3.38 & 3.41 & & & 7.91 & 9.57 & \\
\hline $125-250 \mu \mathrm{m}$ & 2.93 & 3.37 & 3.41 & & & 7.9 & 9.57 & \\
\hline \multicolumn{9}{|l|}{158 Low-Mg } \\
\hline \multicolumn{9}{|l|}{ B } \\
\hline $0-25 \mu \mathrm{m}$ & 2.9 & 3.37 & 3.41 & 3.49 & 3.98 & 7.82 & 9.41 & 11.68 \\
\hline $25-63 \mu \mathrm{m}$ & 2.8 & 3.37 & 3.41 & & & 7.78 & 9.43 & \\
\hline $63-125 \mu \mathrm{m}$ & 2.79 & & & & & 7.75 & 9.42 & \\
\hline $125-250 \mu \mathrm{m}$ & 2.79 & & & & & 7.77 & 9.43 & \\
\hline
\end{tabular}

159 Low-Mg

C

$\begin{array}{lllllllll}0-25 \mu \mathrm{m} & 2.82 & 3.37 & 3.41 & 3.5 & 5.76 & 7.66 & 9.25 & 11.55\end{array}$

$\begin{array}{llllllll}25-63 \mu \mathrm{m} & 2.81 & 3.37 & 3.41 & 3.5 & 5.8 & 7.64 & 9.24\end{array}$

$\begin{array}{llllllll}63-125 \mu \mathrm{m} & 2.8 & 3.37 & 3.41 & 3.5 & 5.81 & 7.63 & 9.25\end{array}$

$\begin{array}{llllll}125-250 \mu \mathrm{m} & 2.8 & 3.37 & 3.41 & 7.62 & 9.25\end{array}$

666 Table 3b: Band positions of the powdered bulk glass size fractions (in $\mu \mathrm{m}$ ). CF = Christiansen Feature; RB $667=$ Strongest Reststrahlenband; TF = Transparency Feature. Features below $6 \mu \mathrm{m}$ are volatile bands.

668 

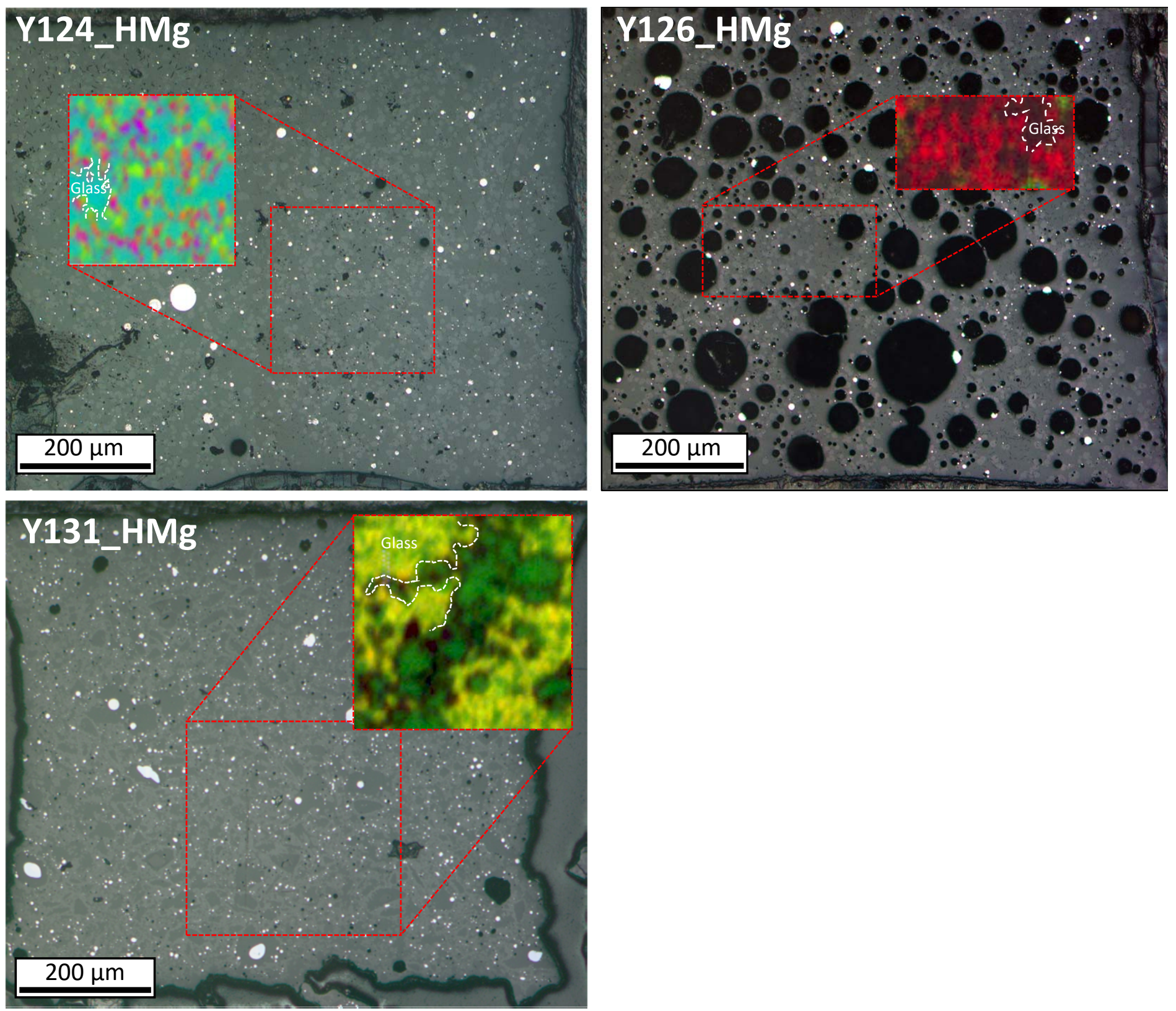

Figure 1 

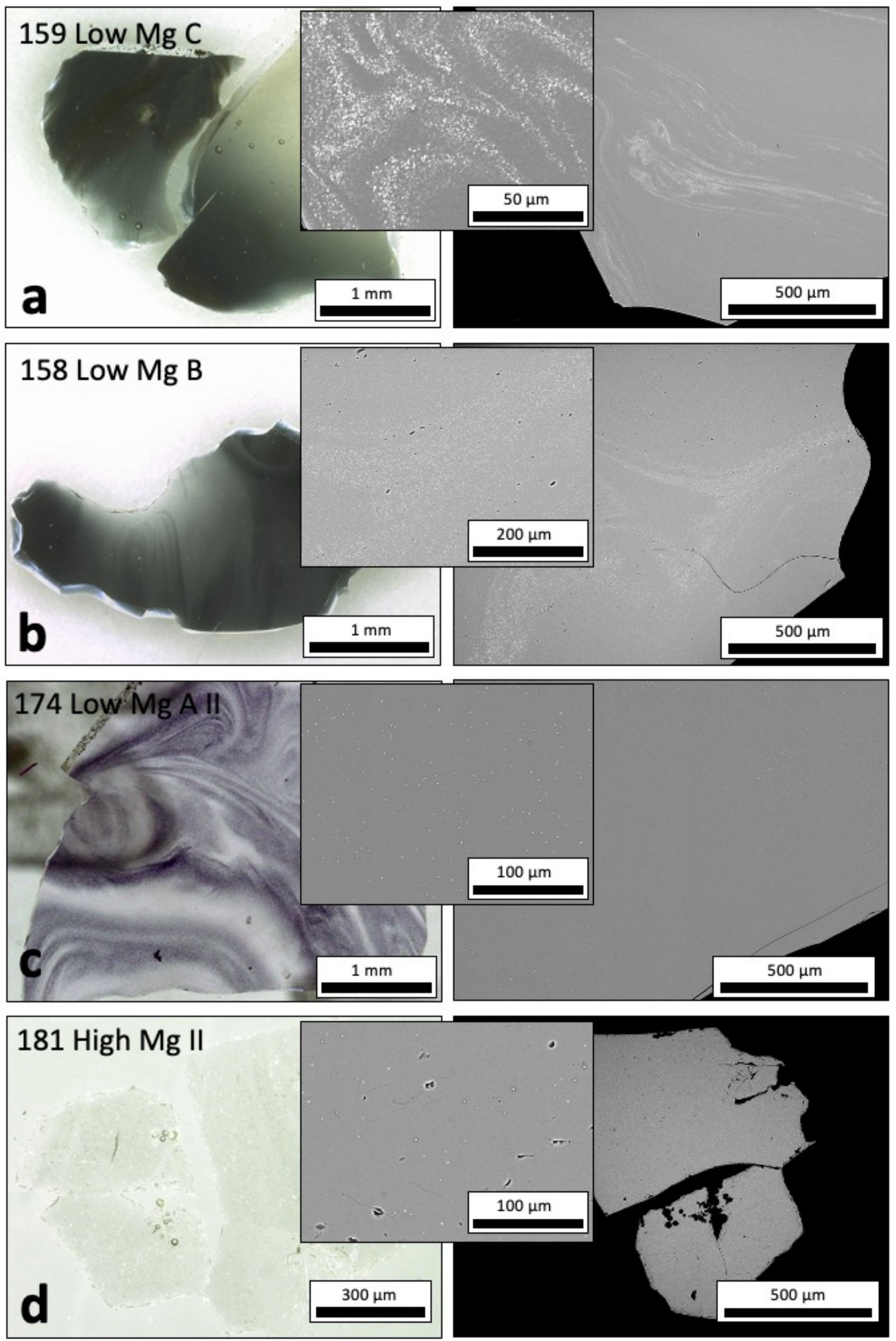

Figure 2 


\section{$\mathrm{Ca} / \mathrm{Si}$}

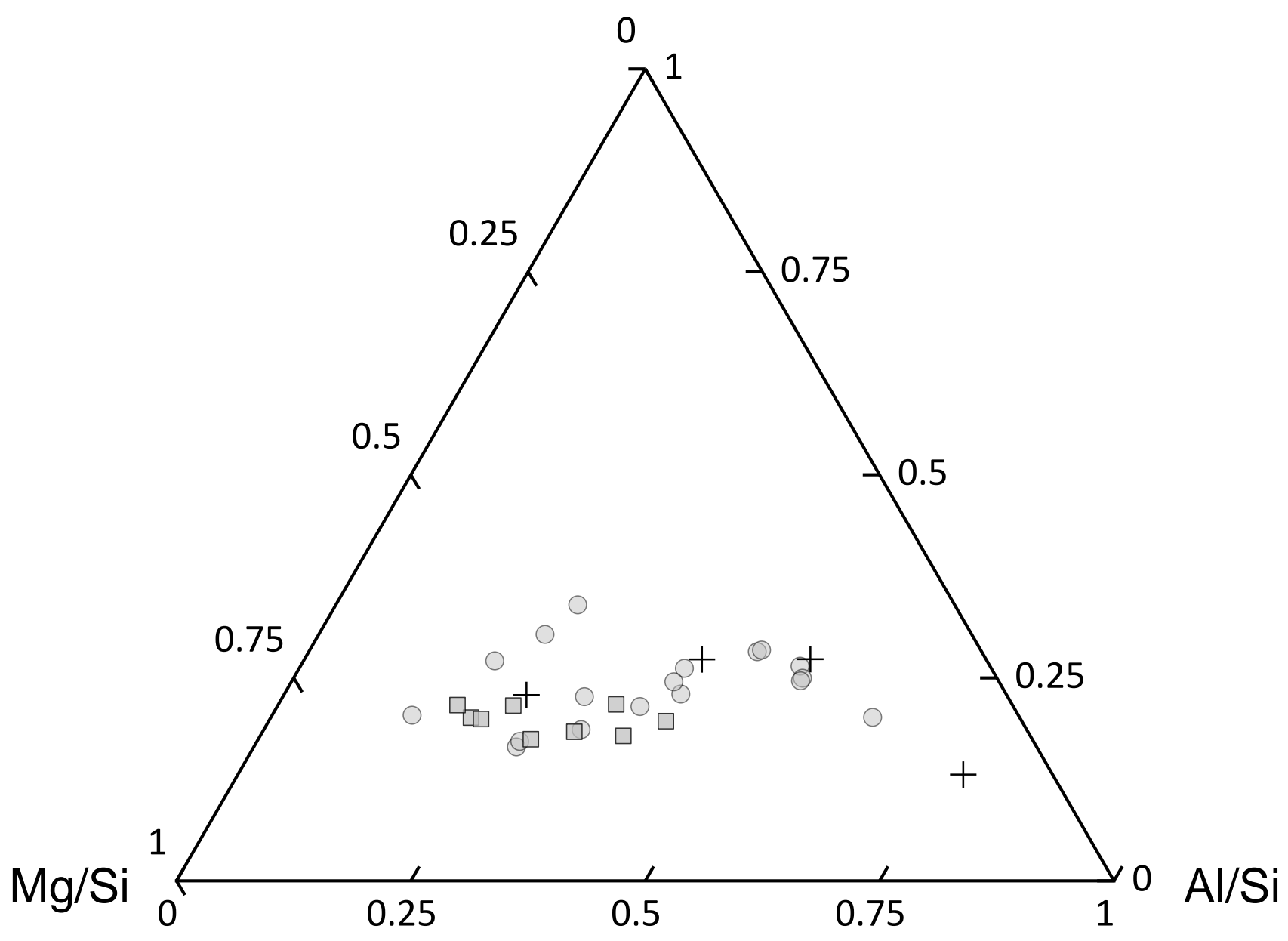

Figure 3 

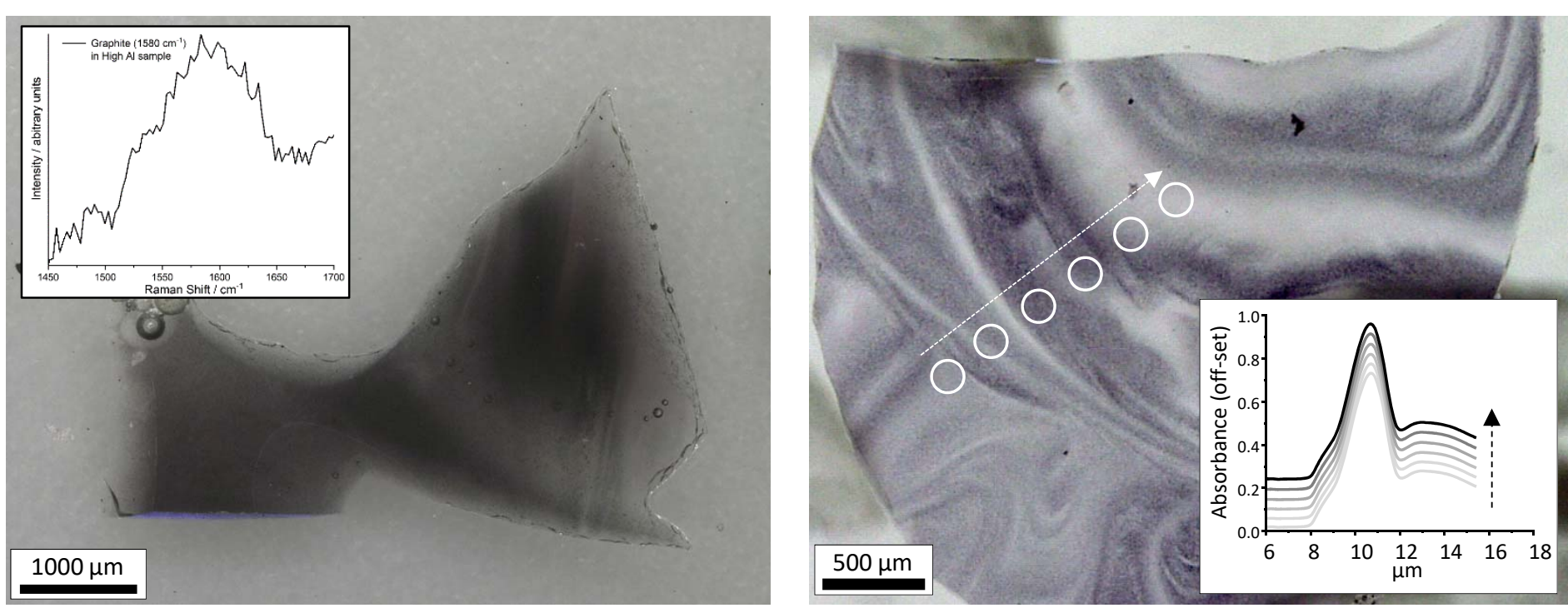

Figure 4 


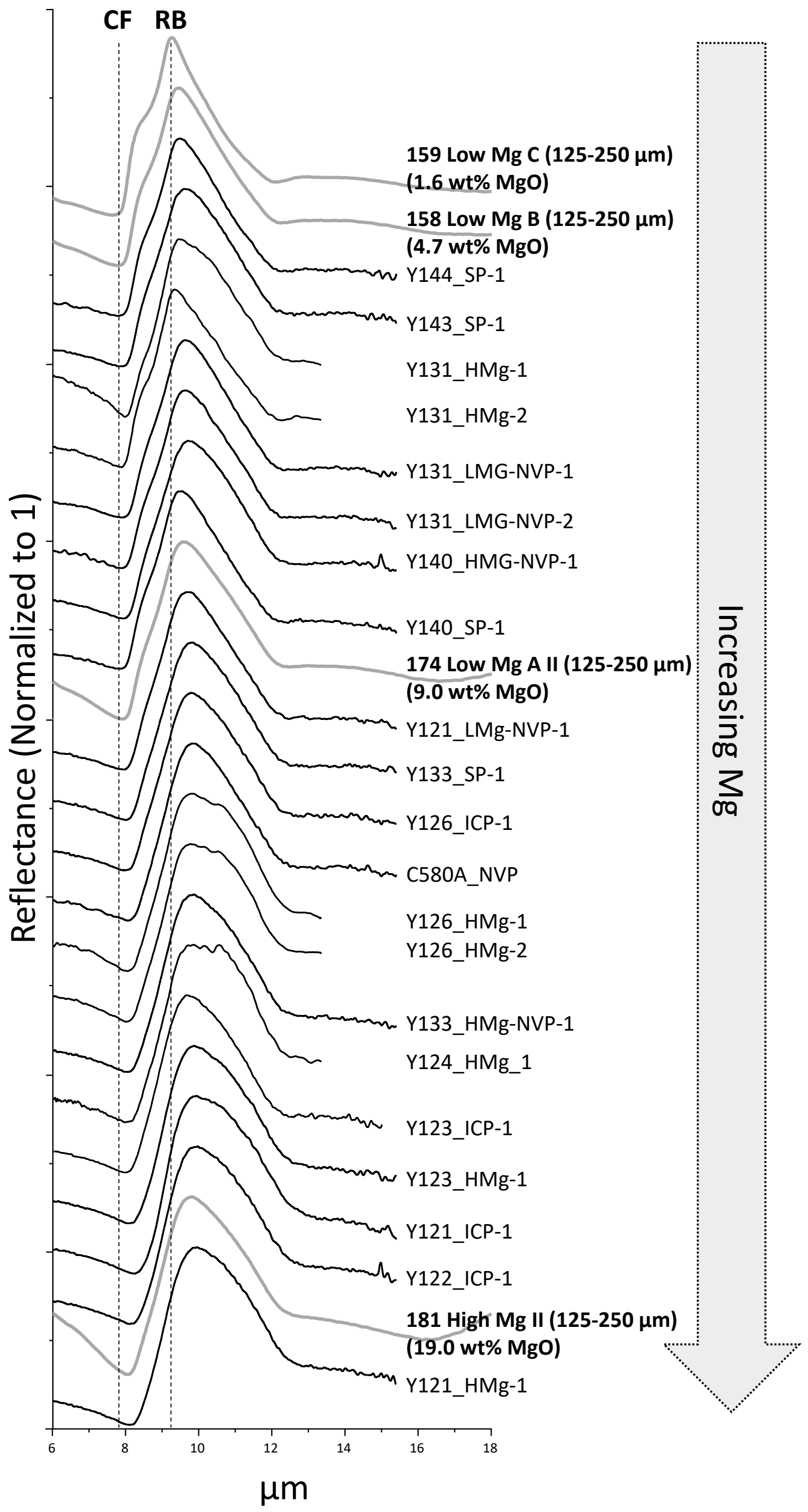

Figure 5 

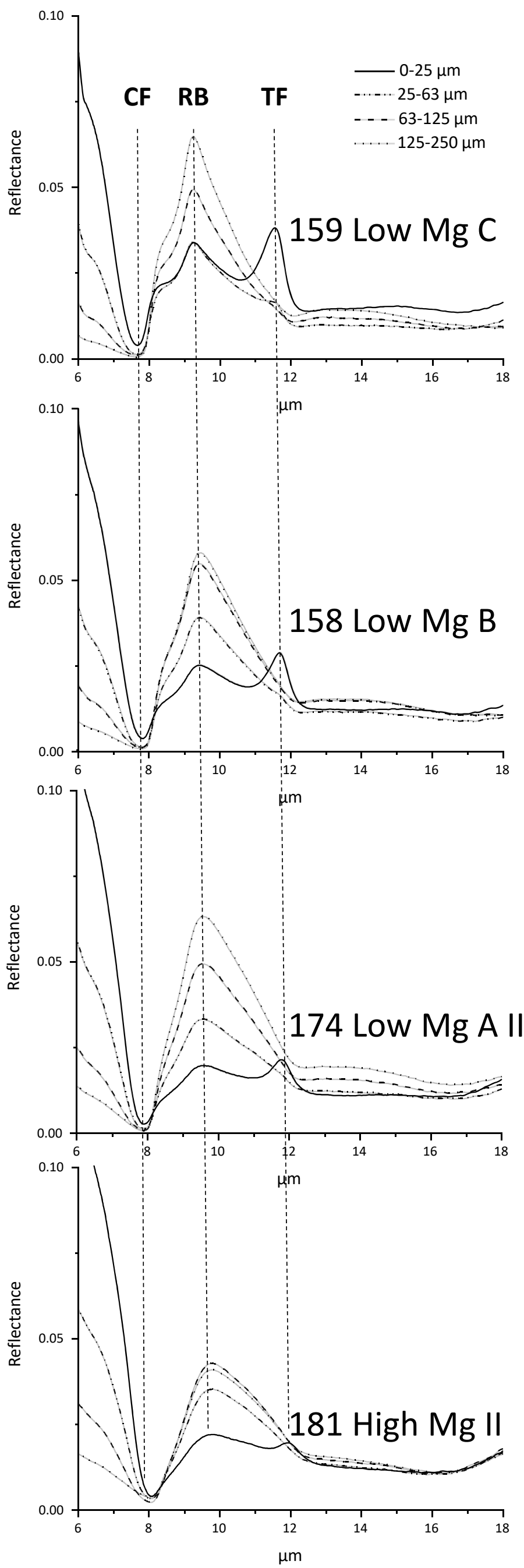

Figure 6 


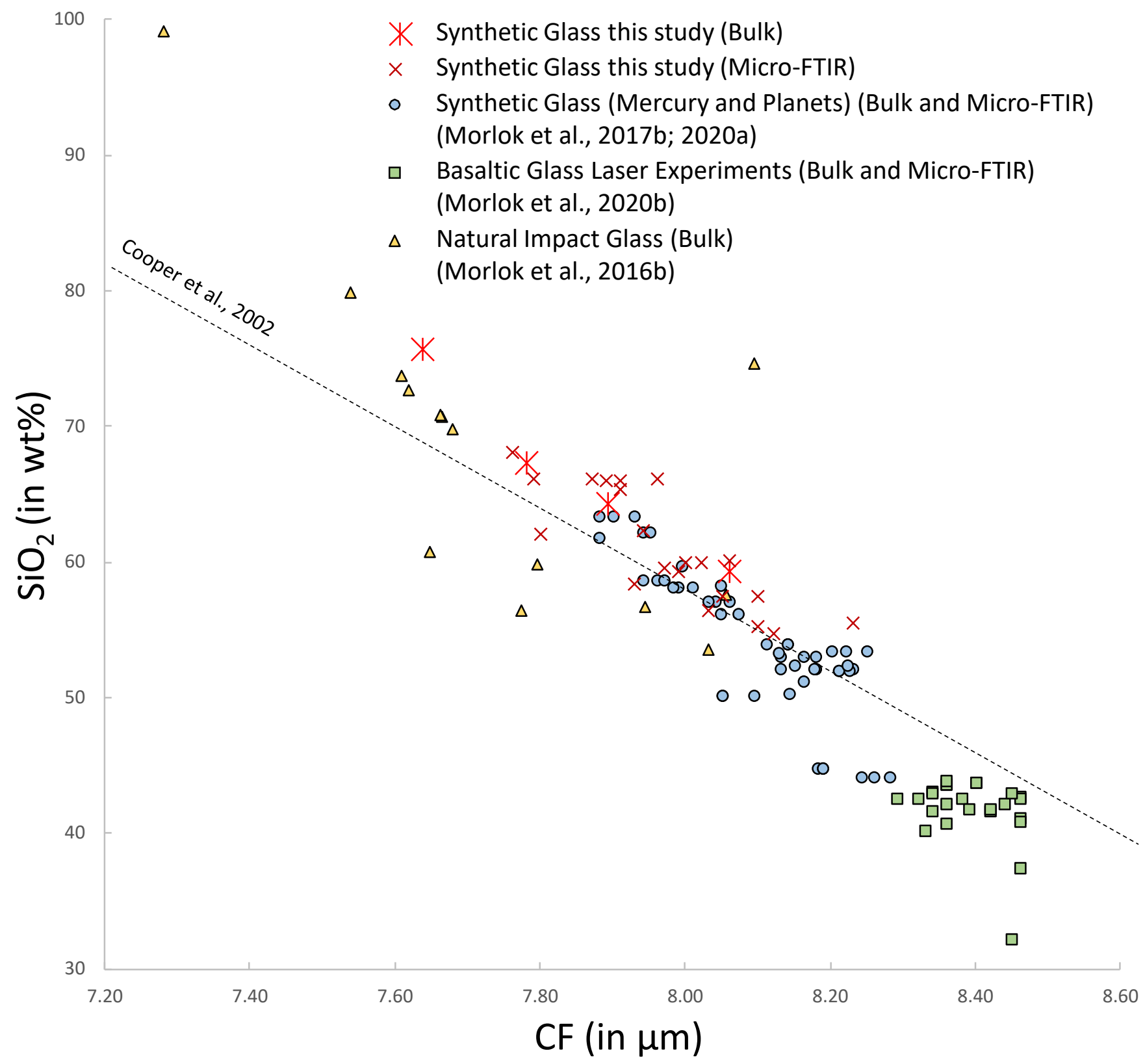

\section{Figure $7 a$}




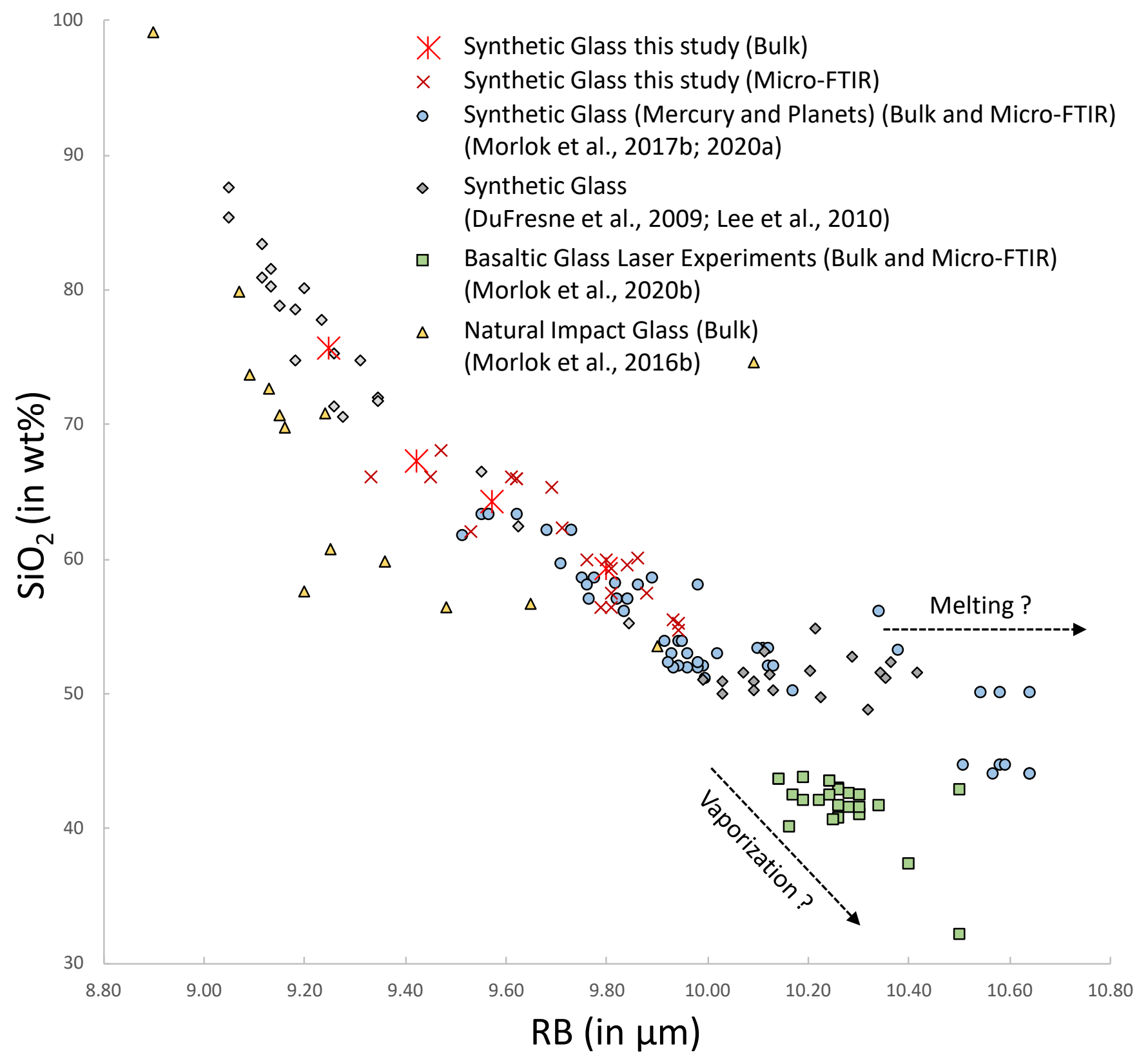

Figure $7 b$ 


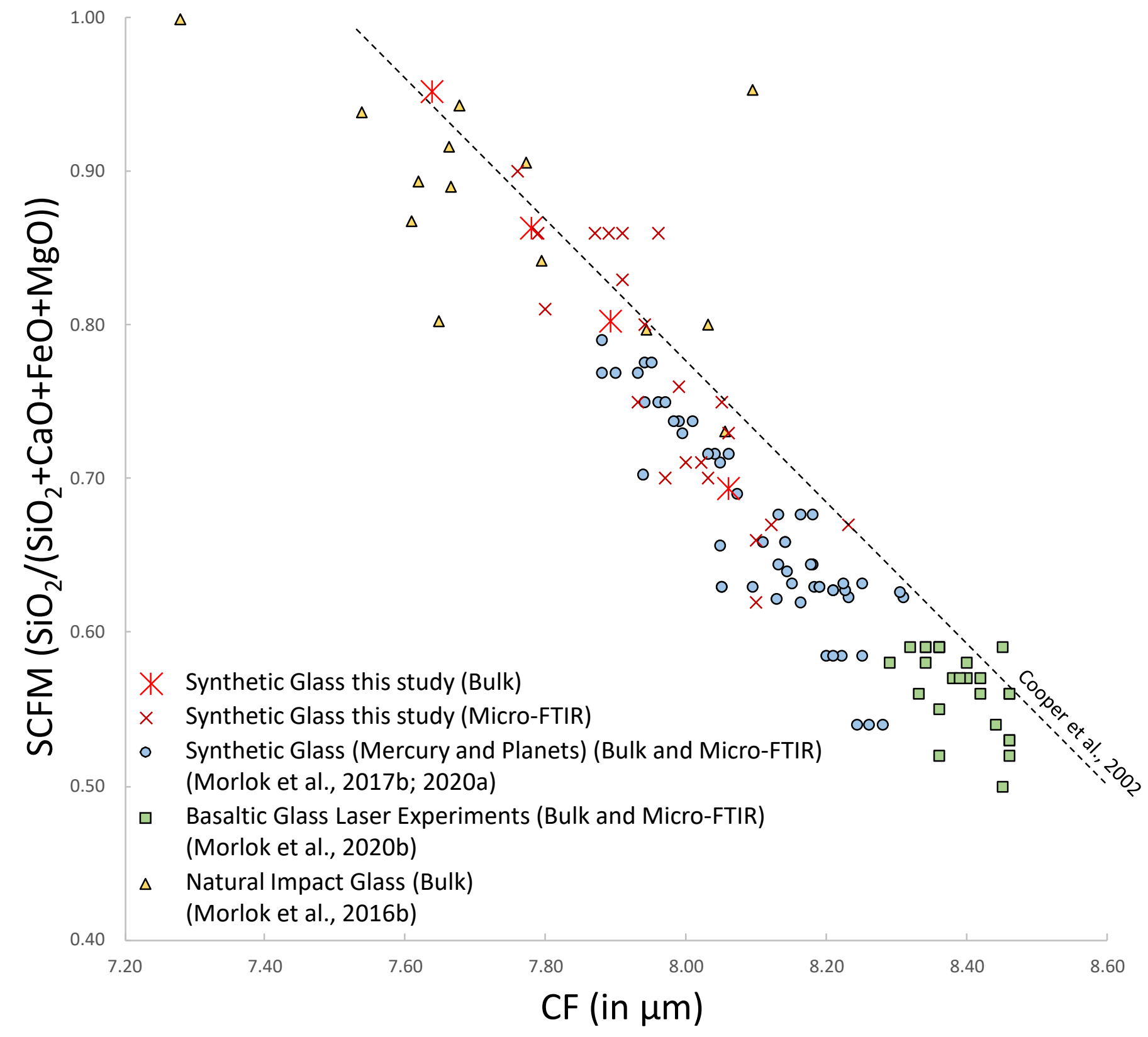

Figure $7 c$ 


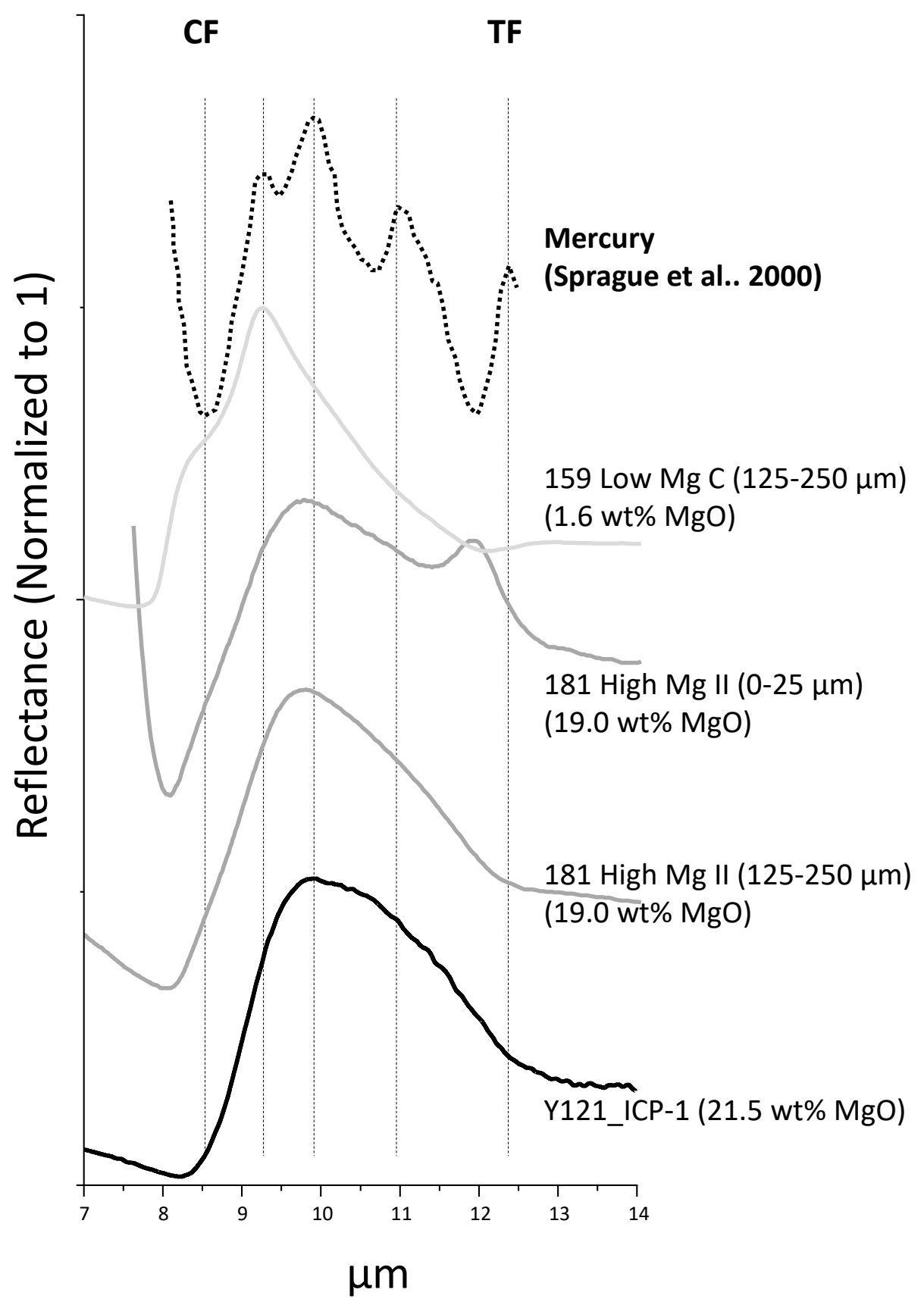

Figure 8 


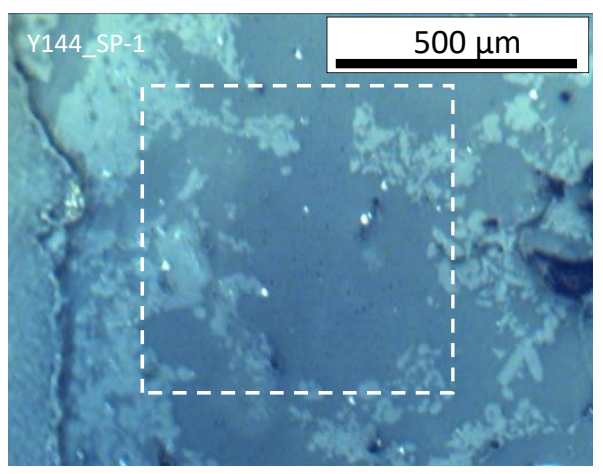

\section{Y140_HMg-NVP-1}
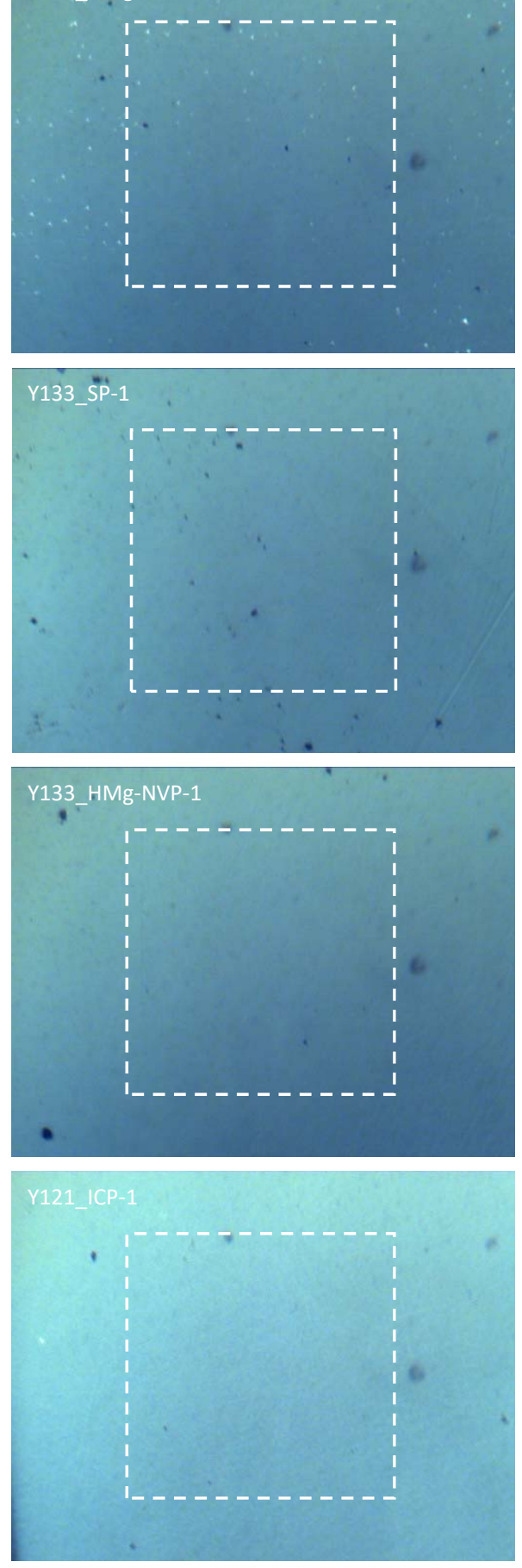

access/download;Figure;FIG_ATTACHMENT_1.pdf
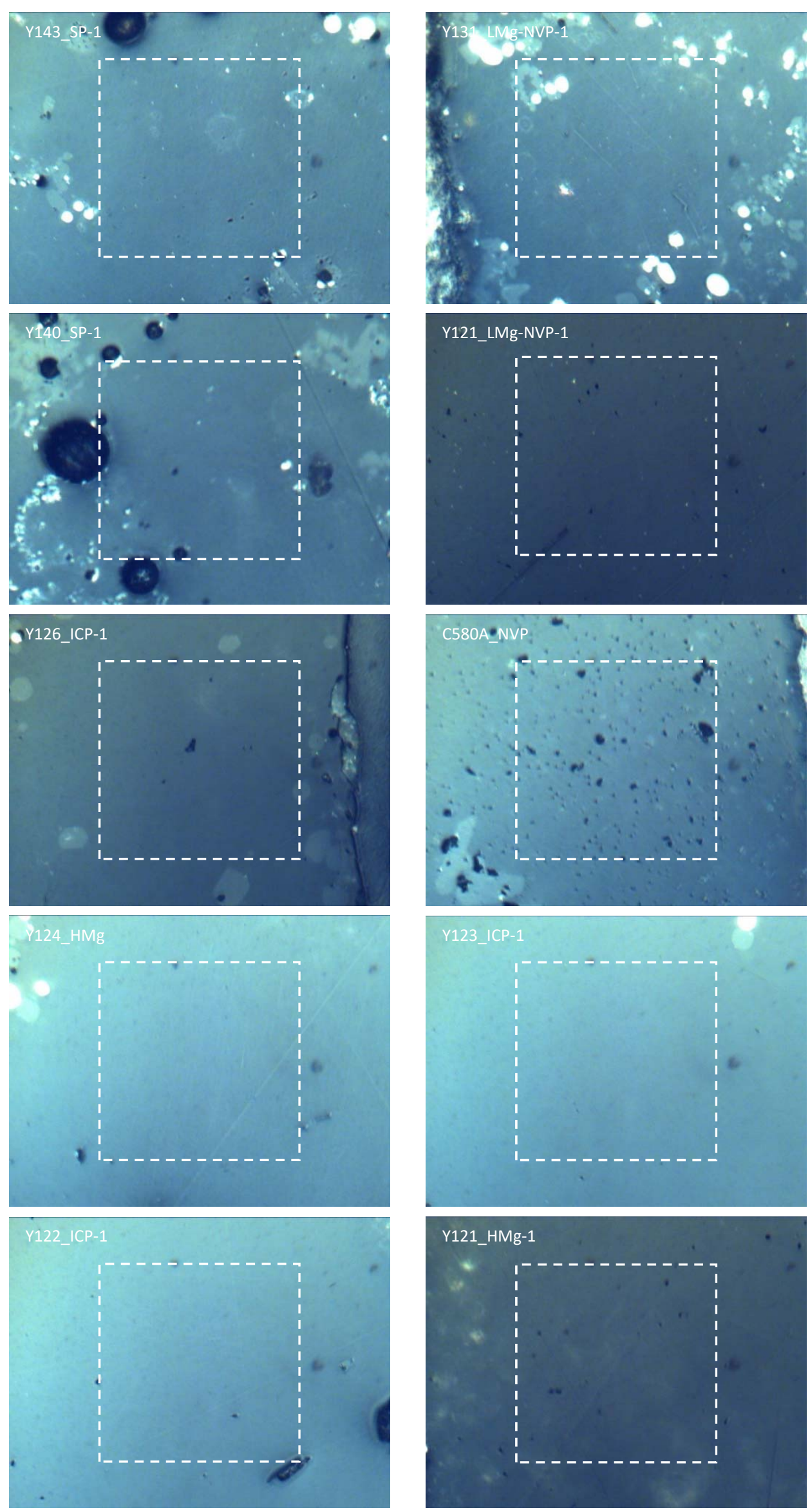
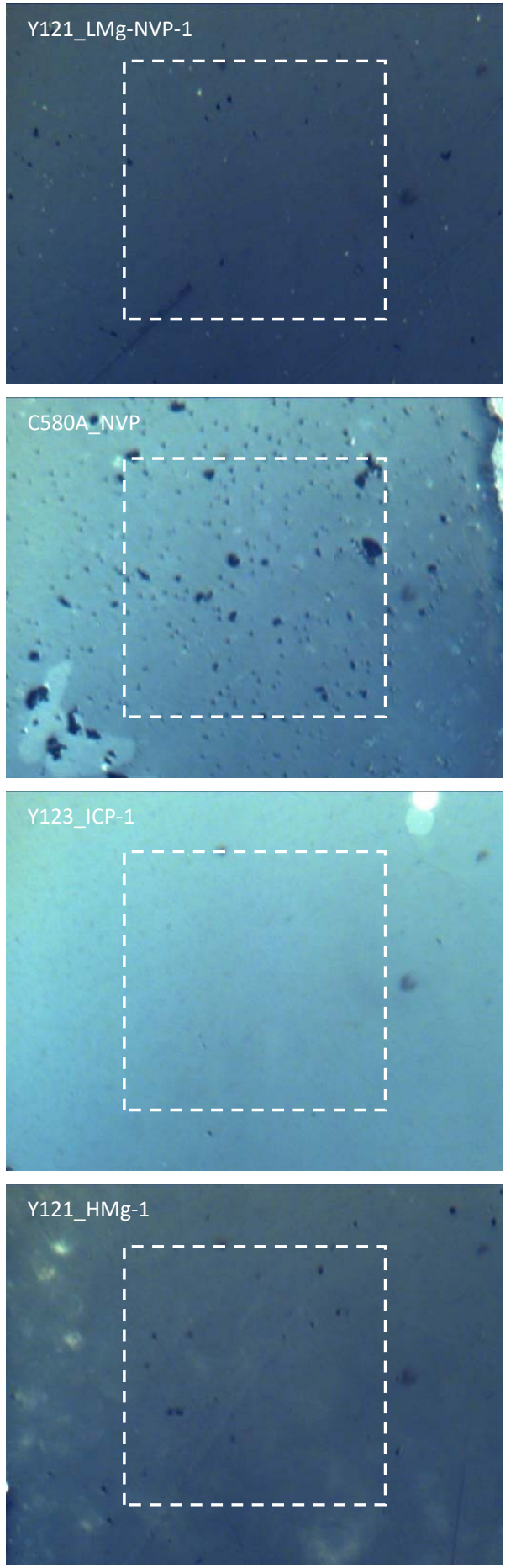

Figure Appendix 1 